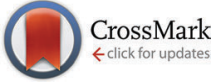

Cite this: Mol. BioSyst., 2016, 12,934

Received 5th November 2015, Accepted 11th January 2016

DOI: $10.1039 / \mathrm{c} 5 \mathrm{mb} 00754 b$

www.rsc.org/molecularbiosystems

\section{Delivery of siRNA using ternary complexes containing branched cationic peptides: the role of peptide sequence, branching and targeting $\dagger$}

\author{
Laila Kudsiova, ${ }^{a}$ Katharina Welser $\ddagger^{\mathrm{b}}$ Frederick Campbell, $\S^{\mathrm{b}}$ Atefeh Mohammadi, ${ }^{\mathrm{b}}$ \\ Natalie Dawson, ${ }^{b}$ Lili Cui, ${ }^{a}$ Helen C. Hailes, ${ }^{b}$ M. Jayne Lawrence ${ }^{a}$ and \\ Alethea B. Tabor*b
}

\begin{abstract}
Ternary nanocomplexes, composed of bifunctional cationic peptides, lipids and siRNA, as delivery vehicles for siRNA have been investigated. The study is the first to determine the optimal sequence and architecture of the bifunctional cationic peptide used for siRNA packaging and delivery using lipopolyplexes. Specifically three series of cationic peptides of differing sequence, degrees of branching and cell-targeting sequences were co-formulated with siRNA and vesicles prepared from a 1:1 molar ratio of the cationic lipid DOTMA and the helper lipid, DOPE. The level of siRNA knockdown achieved in the human alveolar cell line, A549-luc cells, in both reduced serum and in serum supplemented media was evaluated, and the results correlated to the nanocomplex structure (established using a range of physico-chemical tools, namely small angle neutron scattering, transmission electron microscopy, dynamic light scattering and zeta potential measurement); the conformational properties of each component (circular dichroism); the degree of protection of the siRNA in the lipopolyplex (using gel shift assays) and to the cellular uptake, localisation and toxicity of the nanocomplexes (confocal microscopy). Although the size, charge, structure and stability of the various lipopolyplexes were broadly similar, it was clear that lipopolyplexes formulated from branched peptides containing His-Lys sequences perform best as siRNA delivery agents in serum, with protection of the siRNA in serum balanced against efficient release of the siRNA into the cytoplasm of the cell.
\end{abstract}

\section{Introduction}

Small interfering RNA (siRNA) can be used to knock down a wide range of protein targets in viral and cancer cells, raising the possibility that siRNA can be used as a therapy for the treatment of cancers and viral infections. In order for siRNA to be successfully administered in vivo for therapeutic purposes, it must be packaged into nanoparticles in such a way that it is not only protected from enzymatic degradation and aggregation by serum proteins but also targeted to the cell type of interest. Once the target cell has been reached, the siRNA-carrying nanoparticle must then be efficiently internalised, generally via endocytosis. ${ }^{1,2}$

\footnotetext{
${ }^{a}$ Institute of Pharmaceutical Science, King's College London, Franklin-Wilkins Building, 150 Stamford Street, Waterloo Campus, London SE1 9NH, UK

${ }^{b}$ Department of Chemistry, University College London, Christopher Ingold Laboratories, 20, Gordon Street, London WC1H 0AJ, UK. E-mail: a.b.tabor@ucl.ac.uk; Fax: +44(0) 207679 7463; Tel: +44(0) 2076794695

$\dagger$ Electronic supplementary information (ESI) available. See DOI: 10.1039/c5mb00754b ‡ Present address: Sandoz GmbH, Biochemiestraße 10, A-6250 Kundl, Austria.

$\S$ Present address: Leiden Institute of Chemistry, Gorlaeus Laboratories, Einsteinweg 55, 2333 CC Leiden, Netherlands.
}

Although many of the strategies that have been used for packaging and cellular delivery of $\mathrm{DNA}^{3}$ have the potential to be adapted for the delivery of siRNA, siRNA differs from DNA in several crucial respects. ${ }^{4}$ Firstly, the 21 nucleotide base pairs of siRNA are significantly smaller in size than the plasmid DNA usually used for gene delivery, so it is likely that siRNA containing nanoparticle formulations will contain more than one siRNA molecule. In addition, whereas plasmid DNA can be highly condensed by complexation with cationic lipids or polymers to form lipoplexes or polyplexes, siRNA ( 21 base pairs) is unlikely to be significantly condensed, preferring instead to behave as a rigid rod. Finally, although both nanoparticles carrying siRNA and plasmid DNA must both escape from the endosome, plasmid DNA has to reach the nucleus in order for gene expression to occur, whereas siRNA has the advantage of only having to be released into the cytoplasm where it will be loaded onto the multi-protein RNAinducing silencing complex (RISC) thereby initiating the process of sequence-specific degradation of the mRNA targets. ${ }^{4}$

Cationic polymers, which can complex negatively charged siRNA into nanosized particles, have been successfully used for siRNA delivery in vitro. ${ }^{1-4}$ Nanoparticles formulated with 
cationic dendrimers such as poly(amido amine) (PAMAM) have been particularly effective in delivering siRNA for gene silencing. However, very few siRNA delivery systems are currently in preclinical studies or in clinical trials. ${ }^{2}$ One major drawback for clinical applications of cationic dendrimer-containing formulations is their toxicity. Cationic dendrimers are cytotoxic due to their interactions with biological membranes as well as their induced haemolytic and haematological toxicity. ${ }^{5}$ Nanoparticles formulated from siRNA and cationic peptides (either linear or branched) may therefore be an attractive alternative for siRNA delivery, because of their reduced toxicity and their potential biodegradability.

Two approaches to the design of cationic peptide sequences for the complexation and delivery of siRNA to cells have been reported, exploiting either Arg-rich, or mixed His/Lys, sequences of cationic residues. The first approach was based on the observation that cell-penetrating peptides (CPP) are frequently Arg-rich sequences. It is believed that nanoparticles incorporating CPP sequences can translocate directly into cells through the cell membrane, or enter cells via endocytosis. ${ }^{6}$ Indeed non-covalent nanocomplexes of siRNA with ${ }^{7}(\mathrm{~L}-\mathrm{Arg})_{9}$ or with $^{8}(\mathrm{~L}-\mathrm{Arg})_{8}$ have been successfully used to deliver siRNA into cells, with the siRNA localised at the perinuclear region after release from the complex. After uptake of these nanocomplexes into the cells via endocytosis, the CPP may also disrupt the endosomal membrane, allowing the siRNA to be released into the cytoplasm. Kumar et al. used a chimaeric peptide, consisting of a 29-residue sequence of the rabies virus glycoprotein (RVG) linked to a (D-Arg) ${ }_{9}$ sequence, to bind and deliver siRNA to neuronal cells in vitro. ${ }^{9}$ The same complex of chimaeric peptide and siRNA was also used to successfully deliver siRNA to macrophages, ${ }^{10}$ while a CD7-specific single chain antibody conjugated to (D-Arg) ${ }_{9}$ was used to selectively deliver siRNA to $\mathrm{T}$ cells. ${ }^{11}$ In these formulations, it was believed that as the unnatural D-Arg residues are not recognised by enzymes or receptors, these cationic peptides cannot act as CPP and are resistant to serum proteases in vivo. ${ }^{11}$

The second approach was based on the hypothesis that nanocomplexes containing His-rich peptide sequences are able to act as a "proton sponge" and thus to neutralise the acidity of the interior of the endosome. This is believed to lead to swelling and rupture of the endosome with subsequent release of the nanocomplexes into the cytoplasm. ${ }^{12}$ Mixson and co-workers studied highly branched peptide carriers, with different repeating sequences of His and Lys residues in the branches, and targeted with an integrin-binding RGD sequence at the C-terminus, as reagents for the delivery of siRNA. ${ }^{13}$ Significantly, the level of gene knockdown achieved with the best peptide carrier was comparable to or better than the 'gold standards', Lipofectamine 2000 or Oligofectamine but without their associated toxicity. ${ }^{13}$ It was also found that branched peptide carriers based on sequences such as $(\mathrm{HHHK})_{4}$ that resulted in the best level of siRNA delivery, were significantly different from those peptide sequences previously optimised by this group for successful plasmid DNA delivery. These siRNA/(HHHK $)_{4}$ peptide carrier nanocomplexes were also shown to be effective for systemic delivery in vivo. ${ }^{14}$ PEG-modified versions of these nanocomplexes with cRGD targeted ligands showed good pharmacokinetics and tumor-selective siRNA delivery in vivo. ${ }^{15,16}$ Linear, amphipathic histidine-rich peptide sequences, which also contain Lys, Ala and Leu residues, have also been reported to be effective for siRNA delivery, ${ }^{17}$ and disulfide-linked polymers of Cys-His-Lys peptides ${ }^{18}$ have been used to deliver a broad range of nucleic acids, including siRNA. ${ }^{19}$

The gene delivery properties of ternary nanocomplexes, known as lipopolyplexes, composed of lipid, peptide and DNA, have recently been investigated, using: a bifunctional peptide with a (Lys) ${ }_{16}$ domain to bind and condense DNA and a cyclic peptide targeting domain that partially protrudes from the nanocomplex and mediates cell-specific receptor-mediated endocytosis of the vector; ${ }^{20}$ and a $1: 1$ mixture of a cationic lipid, structurally related to $N$-[1-(2,3-dioleyloxy)propyl]- $N, N, N$-trimethylammonium chloride (DOTMA), and the neutral lipid, dioleylphosphatidylethanolamine (DOPE) (which can enhance liposome fusion with the endosomal membrane, leading to endosomal escape ${ }^{21}$ ). This vector has been optimised for a number of applications, including the development of a peptide targeting sequence for gene delivery to respiratory cells. ${ }^{22}$ Shielding lipids containing short ethylene glycol (EG) sequences, ${ }^{23-25}$ and peptides that are cleaved within the endosome ${ }^{25}$ to give vectors that are stable in the systemic circulation but disassemble once internalized, ${ }^{25,26}$ have been incorporated. The effect of lipid chain geometry on the structure and transfection properties of lipopolyplexes and lipoplexes (binary complexes of lipid and DNA) has also been investigated. ${ }^{27,28}$ Most recently, the effect of cationic residue sequence and branching on the level of plasmid DNA deliver achieved with lipopolyplexes has been studied, with branched Arg-rich peptides and linear Lys-rich peptides being most effective. ${ }^{29}$

In this work, the effects of varying the sequence of cationic residues and the degree of branching on the packaging and delivery of siRNA in DOTMA:DOPE:peptide:siRNA lipopolyplexes (LPRs) have been studied. In light of the various studies on polyplex delivery of siRNA reported by other groups, we have for the first time carried out a detailed comparison of whether Lys, His, L-Arg, D-Arg or mixed His/Lys sequences would be most effective in mediating siRNA delivery, in both peptide:siRNA polyplexes (PR) and LPR formulations. We have also investigated the effect of peptide sequence and structure on the overall structure, siRNA protection, and cytoplasmic release of the nanocomplex, and are able to relate this to the effectiveness of the LPRs as siRNA delivery vehicles.

\section{Results}

\section{Peptide design}

A comprehensive set of linear (B0), singly (B1) and doublybranched polycationic peptides (B2) has been studied to explore the effect of both cationic sequence and peptide structure on the complexation of siRNA and the gene silencing efficiency of LPRs. To test the LPRs in a human alveolar cell line, the peptide sequences included a targeting sequence, CYGLPHKFC (sequence [Y]) which was selected by phage display to bind human airway epithelial cells and mediate good DNA transfection efficiency. ${ }^{22}$ 
The targeting [Y] and polycationic sequences are linked by either a non-cleavable spacer sequence (GAGA (L2)) or a cleavable sequence (RVRRGA (L1)). L1 is recognised by the endosomal enzyme furin, and peptides containing this sequence have been previously demonstrated to enhance DNA transfection by LPD complexes. ${ }^{25,26}$

Three groups of peptides were synthesised for formulation and testing. In Group 1 we aimed to compare the effects of Lys, Arg, D-Arg and His residues in peptides of the same length and degree of branching (Fig. 1). In order to determine whether or not the targeting sequence plays a major role in cellular uptake a control, $\mathbf{S K}_{\mathbf{6}} \mathbf{B 1}-\mathbf{L 1}-[\mathbf{Y}]$, with a scrambled version of the [Y] sequence, was prepared. The Group 2 peptides are designed to compare the effects of linear, singly and doubly branched peptides on LPR knockdown, and a second control peptide, $\mathbf{K}_{\mathbf{1 2}}$, (devoid of a targeting sequence) has also been included to investigate the role of the targeting sequence. Four peptides (Group 3) based on the alternating HK sequences recently reported by Mixson and co-workers, ${ }^{13}$ were also studied. In this paper, repeating HHHK sequences in 4-branched and 8-branched peptides were found to be particularly effective in siRNA delivery, and therefore the singly-branched peptides $\left(\mathbf{H}_{\mathbf{3}} \mathbf{K}\right)_{\mathbf{4}} \mathbf{B 1}-\mathbf{L 1}-[\mathbf{Y}]$ and $\left(\mathbf{K H}_{3}\right)_{\mathbf{4}} \mathbf{B 1}-\mathbf{L 1}-[\mathbf{Y}]$ were prepared. In contrast, Mixson and co-workers reported that HHK sequences were less effective for siRNA delivery but gave better pDNA transfection, and the peptide (HHK) $)_{4}$ B1-L1-[Y] was therefore also studied. As a further comparison, a fourth peptide based on a repeating HHHHK sequence, $\left(\mathbf{H}_{4} \mathbf{K}\right)_{3} \mathbf{B 1}$-L1-[Y] was synthesised. All LPRs were prepared using vesicles comprising of a $1: 1$ molar ratio of cationic lipid, DOTMA, and neutral helper lipid, DOPE, (Lipofectin ${ }^{\circledR}$ ). For the purposes of comparison the biophysical and transfection properties of PRs, prepared by complexing the various peptides with siRNA, were investigated.

\section{In vitro knockdown experiments}

Knockdown experiments with LPRs, made using the various peptides at charge ratios of $0.5: 6: 1$ or $0.5: 12: 1$ and prepared either in water and diluted 1 in 4 in OptiMEM (water/OptiMEM) or OptiMEM diluted 1 in 4 with serum-containing growth medium (OptiMEM/Medium), were performed in a stably transfected A549-Luc cell line (Fig. 2). A comparable level of knockdown to the (water/OptiMEM) experiment was achieved when LPRs were prepared fully in OptiMem, and little knockdown was achieved when LPRs were prepared in water and diluted 1 in 4 with serum-containing growth medium (water/Medium) (Fig. S1, ESI $\dagger$ ). For comparison, the knockdowns obtained with PRs when formulated fully in OptiMEM are given in Fig. S2, ESI. $\dagger$

High levels of knockdown were achieved in the water/OptiMEM preparation (Fig. 2a-c), and when LPRs were prepared fully in OptiMEM (Fig. S1a-c, ESI $\dagger$ ), for the majority of peptide sequences.
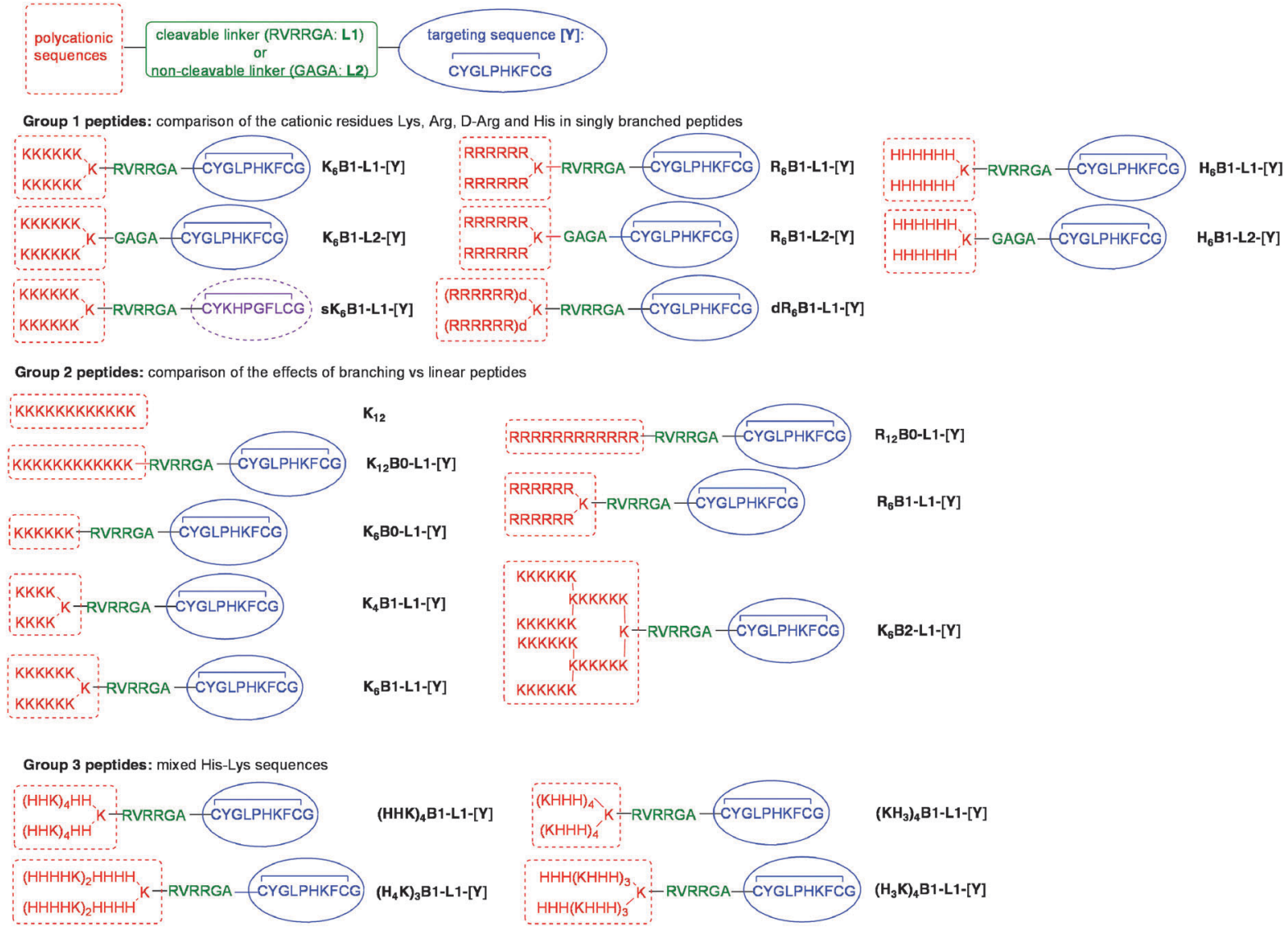

Fig. 1 Structures of Group 1, Group 2 and Group 3 peptides. 

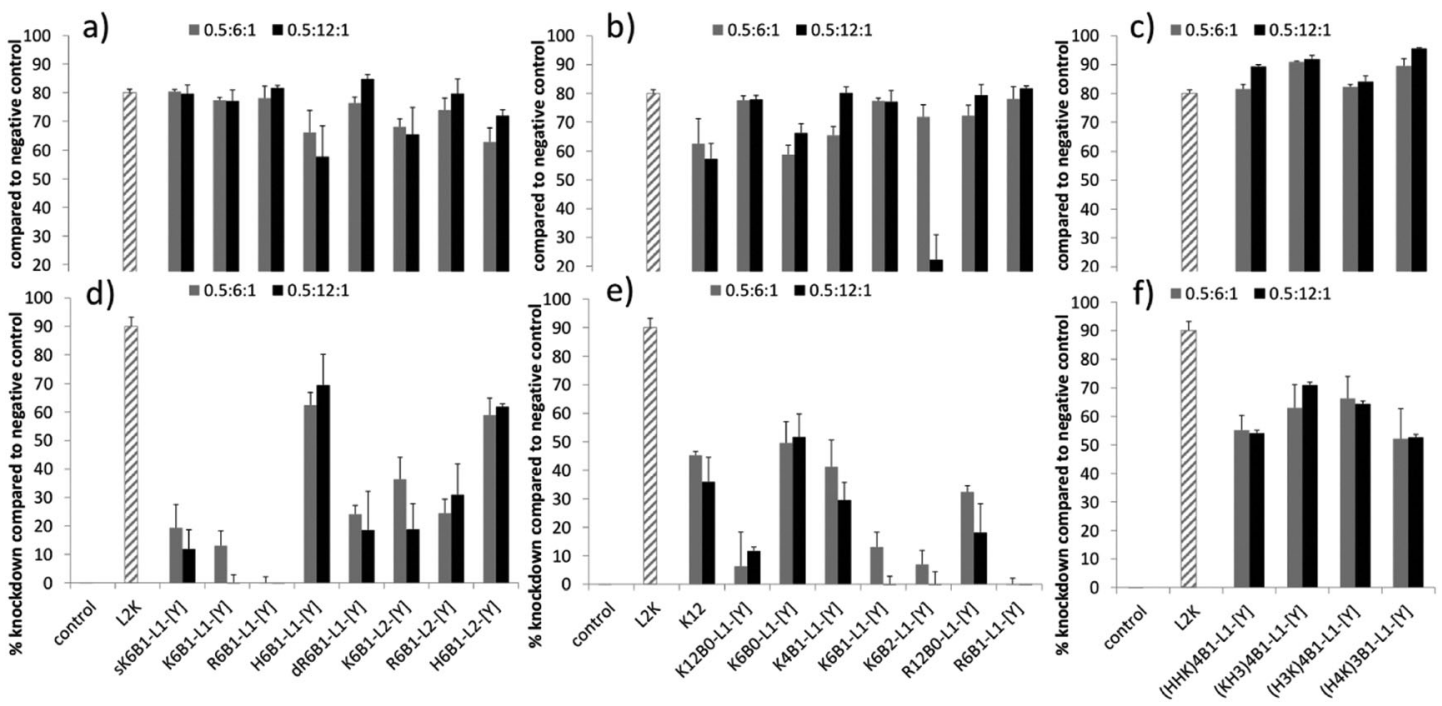

Fig. 2 Percentage knockdown (calculated as \% using luminescence produced by each complex when formulated with negative control siRNA and normalised according to the protein content) of LPRs at 0.5:6:1 (grey bars) or 0.5:12:1 (black bars) charge ratios, prepared using (a and d) Group 1, ( $b$ and e) Group 2, and ( $c$ and f) Group 3 peptides. LPRs were prepared either in ( $a-c$ ) water then diluted in OptiMEM (water content $=12.5 \%$ v/v); or in $(d-f)$ in OptiMEM then diluted in serum-containing growth media (OptiMEM content $=12.5 \% \mathrm{v} / \mathrm{v}$ ). siRNA alone and L2K : siRNA at $5: 1$ weight ratio were used as controls. siRNA concentration was $50 \mathrm{nM}$ per well.

Poor or negligible knockdown was obtained with the PRs prepared under the same conditions, clearly showing the benefit of formulating LPRs rather than PRs.

The greatest level of knockdown, in fact greater than that exhibited by the positive control, L2K, was observed with LPRs prepared using Group 3 peptides (Fig. 2c). These Group 3 peptides included the HHHK sequences identified by Mixson and co-workers ${ }^{13}$ as highly effective for siRNA delivery (peptides $\left(\mathbf{K H}_{3}\right)_{\mathbf{4}} \mathbf{B 1}-\mathbf{L 1}-[\mathbf{Y}]$ and $\left.\left(\mathbf{H}_{3} \mathbf{K}\right)_{\mathbf{4}} \mathbf{B 1}-\mathbf{L 1}-[\mathbf{Y}]\right)$ as well as two other alternating HK sequence peptides. Furthermore, with the exception of doubly branched $\mathbf{K}_{\mathbf{6}} \mathbf{B 2}-\mathbf{L} \mathbf{1}-[\mathbf{Y}]$ peptide (and $\mathbf{K}_{\mathbf{6}} \mathbf{B 1}-\mathbf{L} \mathbf{1}-[\mathbf{Y}]$ and $\mathbf{K}_{\mathbf{1 2}} \mathbf{B 0}$-L1-Y when prepared fully in OptiMEM) increasing the charge ratio of the peptide in the LPR from $0.5: 6: 1$ to $0.5: 12: 1$ in the LPR formulations prepared in OptiMEM or water/OptiMEM did not significantly influence knockdown efficiency. This result is in contrast to LPD formulations, where DNA transfection increased upon increasing charge ratio of the peptide from $0.5: 6: 1$ to $0.5: 12: 1 .^{29}$

LPRs formulated in water/OptiMEM using the Group 1 peptides did not show major differences in knockdown efficiency (Fig. 2a). Furthermore, no difference in knockdown efficiency was seen when comparing LPRs prepared using peptides containing the enzymatically cleavable RVRRGA (L1) linker to those possessing the non-cleavable GAGA (L2) linker. It is also notable that the control peptide, $\mathbf{S K}_{\mathbf{6}} \mathbf{B 1}-\mathbf{L 1}-[\mathbf{Y}]$, with a scrambled version of the [Y] sequence, gave similarly good knockdown results, suggesting that under these conditions receptor binding and uptake of the LPR complexes is also not the crucial step for knockdown. Finally, whilst the His-containing peptides $\mathbf{H}_{6} \mathbf{B 1}-\mathbf{L 1}-[\mathbf{Y}]$ and $\mathbf{H}_{6}$ B1-L2-[Y] should have a lower charge at $\mathrm{pH} 7$ when compared to the other sequences, this also does not have any influence on knockdown efficiencies.
LPRs containing the singly branched peptides in Group 2, $\mathbf{K}_{\mathbf{4}} \mathbf{B 1}-\mathbf{L 1}-[\mathbf{Y}]$ and $\mathbf{K}_{\mathbf{6}} \mathbf{B 1}-\mathbf{L 1}-[\mathbf{Y}]$, were slightly more effective knockdown agents than the LPRs with the linear $\mathbf{K}_{\mathbf{6}} \mathbf{B 0}$-L1- $[\mathbf{Y}]$ in water/ OptiMEM. However, the extent of peptide branching did not play a significant role in knockdown as further branching of the peptide ( $\left.\mathbf{K}_{\mathbf{6}} \mathbf{B} 2-\mathbf{L} 1-[\mathbf{Y}]\right)$ did not improve knockdown efficiency (Fig. 2b). A further control peptide, $\mathrm{K}_{16}$, lacking any targeting sequence, also gave equally good knockdown results.

The effect of the presence of serum on the knockdown efficiency of the LPRs was also examined. It is of particular note that LPRs prepared in water and diluted in media containing 10\% FBS showed very poor knockdown efficiencies, as did indeed the positive control when prepared under the same conditions (Fig. S1, ESI $\dagger$ ).

This poor knockdown is attributed to the presence of negatively charged serum proteins, present in the growth media, neutralizing the cationic charge of the LPRs, most probably leading to their aggregation and thereby reducing their interaction with the negatively charged cell. In contrast, when the LPRs were prepared in OptiMEM and diluted in growth media (Fig. 2d-f), the knockdown activity of a number of the complexes, including those containing L2K was, at least partially, maintained.

The lower knockdown efficiencies seen in the presence of serum revealed differences in the extent of knockdown achieved using the various peptides, making certain interesting trends clear. Firstly, as with the LPRs prepared in water and then OptiMEM, and indeed fully in OptiMEM, no difference was seen in increasing the charge ratio of the peptide in the LPR from $0.5: 6: 1$ to $0.5: 12: 1$. Secondly, in the presence of serum the greatest knockdown was achieved using peptides containing histidine - in particular the results obtained using the Group 3 
peptides which achieved knockdowns of up to $\sim 70 \%$, with LPRs containing $\left(\mathbf{K H}_{3}\right)_{\mathbf{4}} \mathbf{B 1}-\mathbf{L 1}-[\mathbf{Y}]$ and $\left(\mathbf{H}_{3} \mathbf{K}\right)_{\mathbf{4}} \mathbf{B 1}-\mathbf{L 1}-[\mathbf{Y}]$ being most effective. Similarly, within the Group 1 peptides (Fig. 2d), the complexes prepared using the His-containing peptides, $\mathbf{H}_{6}$ B1-L1-[Y] and $\mathbf{H}_{6}$ B1-L2-[Y] produced the greatest knockdown while LPRs prepared using $\mathbf{K}_{\mathbf{6}} \mathbf{B 1}-\mathbf{L 1}-[\mathbf{Y}]$ and $\mathbf{R}_{\mathbf{6}} \mathbf{B 1}-\mathbf{L 1}-[\mathbf{Y}]$ showed no activity whatsoever.

Again, with the exception of LPRs containing the peptides, $\mathbf{H}_{6}$ B1-L1-[Y] and $\mathbf{H}_{6}$ B1-L2-[Y], LPRs prepared (OptiMEM/ Medium) using peptides containing the non-cleavable GAGA (L2) linker showed significantly better activity in the presence of serum than those containing the cationic Arg-rich RVRRGA (L1) linker. LPRs containing $\mathbf{d R}_{\mathbf{6}} \mathbf{B 1}$-L1-[Y] were more effective than those containing $\mathbf{R}_{\mathbf{6}} \mathbf{B} \mathbf{1}-\mathbf{L 1}-[\mathbf{Y}]$ (Fig. 2d). In addition, as can be seen from a consideration of the results obtained using the Group 2 peptides (Fig. 2e), increasing the degree of branching and number of cationic peptide residues in the Lys and Arg was detrimental to knockdown efficiency for LPRs. For example, the best knockdown was produced by LPRs containing the linear peptide, $\mathbf{K}_{\mathbf{6}} \mathbf{B 0}$-L1-[Y], followed by the Lys containing singly branched peptide $\mathbf{K}_{\mathbf{4}} \mathbf{B 1}-\mathbf{L 1}-[\mathbf{Y}]$, next $\mathbf{K}_{\mathbf{6}} \mathbf{B 1}-\mathbf{L 1}-[\mathbf{Y}]$ and finally the doubly branched $\mathbf{K}_{\mathbf{6}} \mathbf{B 2}-\mathbf{L 1}-[\mathbf{Y}]$. Finally, complexes prepared using the linear Lys containing peptide, $\mathbf{K}_{\mathbf{1 2}} \mathbf{B 0}$-L1-[Y], were less effective than those using $\mathbf{K}_{\mathbf{6}} \mathbf{B 0}-\mathbf{L 1}-[\mathbf{Y}]$, or a $\mathbf{K}_{\mathbf{1 2}}$ peptide devoid of targeting or linker sequences.

The toxicity exerted by the LPRs was measured indirectly using the protein assay (Fig. S3, ESI $\dagger$ ). Most of the LPRs tested, regardless of their method of preparation, showed over $80 \%$ cell viability compared to untreated controls. In contrast however, the L2K containing lipoplexes exerted the lowest cell viability at $\sim 70 \%$. Interestingly, LPRs prepared in the presence of serum-containing media showed higher viability than those prepared fully in OptiMEM or water/OptiMEM.

\section{Dynamic light scattering and zeta potential}

The apparent hydrodynamic size and zeta potential of the LPRS and PRs are shown in the ESI $\dagger$ (Fig. S4 and S5, respectively). The LPRs were small, being typically in the size range 45-75 nm and were positively charged with zeta potentials of between 12-50 mV, with the majority of LPRs exhibiting a zeta potential of greater than $30 \mathrm{mV}$. No correlation was observed between LPR size, zeta potential and the peptide ratio and structure of the peptide used to prepare the LPR, although there was a clear tendency for the LPRs containing His or His-rich peptides to exhibit lower zeta potentials.

In contrast, the apparent hydrodynamic diameters of the PRs were much larger at up to $1500 \mathrm{~nm}$ and more polydisperse suggesting the presence of much more highly aggregated particles. Although the zeta potentials of the PRs were positive, typically in the range 5-38 $\mathrm{mV}$ (with the exception of PRs containing $\left(\mathbf{H}_{\mathbf{4}} \mathbf{K}\right)_{3} \mathbf{B} 1-\mathbf{L 1}-[\mathbf{Y}]$ which were negative, probably due to the lower charge on the peptide at neutral $\mathrm{pH}$ ) they were noticeably lower than the corresponding LPRs. This suggests that the cationic lipid plays a significant role in the structure of the complexes both in terms of complex size and charge.

\section{Transmission electron microscopy}

In agreement with dynamic light scattering measurements, transmission electron microscopy (TEM) imaging of selected LPR and PR formulations showed that the LPRs were small, homogeneous electron dense, spherical particles with no internal structure visible (Fig. 3a-e) while the PRs were much more heterogeneous, demonstrating extensive aggregation (Fig. S6 ESI $\dagger$ ). By way of comparison, LR complexes prepared from DOTMA: DOPE:siRNA at 0.5:1 charge ratio showed particles containing a lamellar structure (indicated by the arrow in Fig. 3f) typically seen

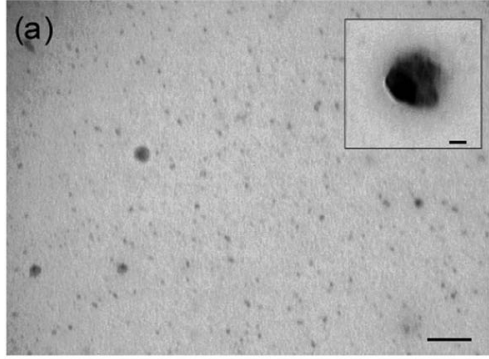

(d)

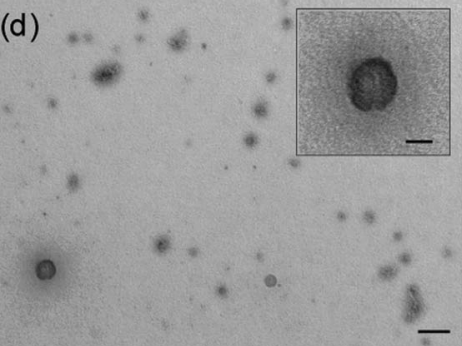

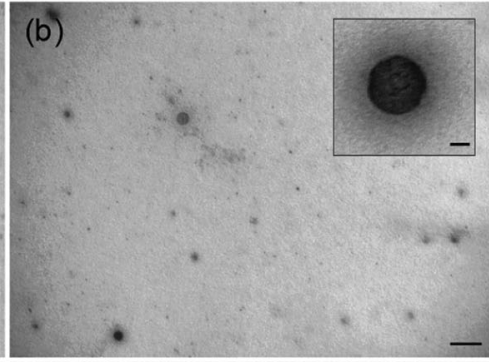
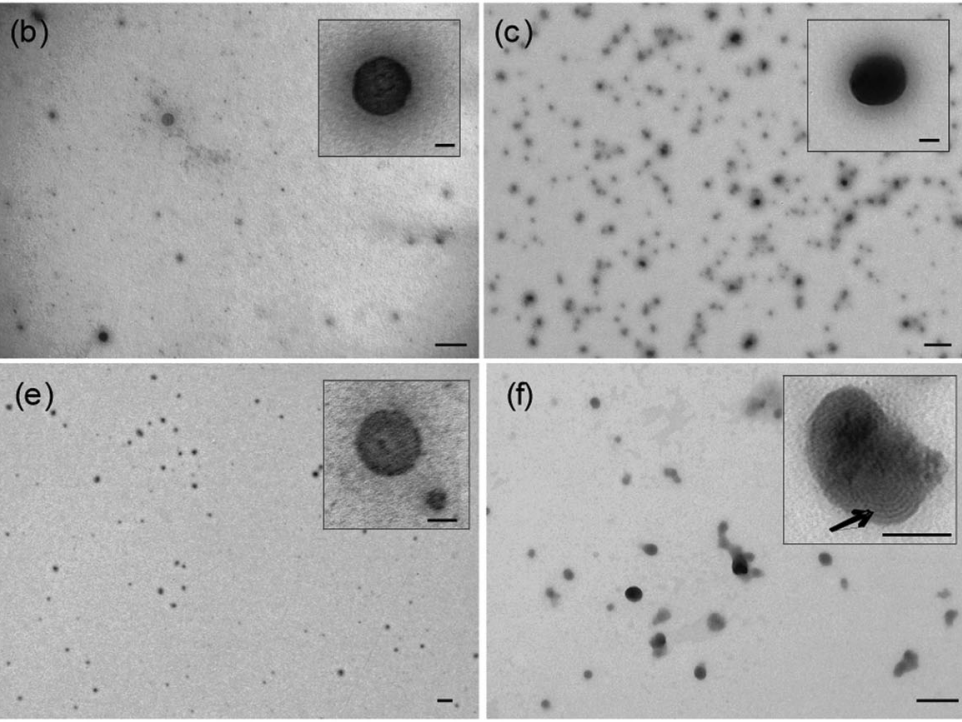

(f)
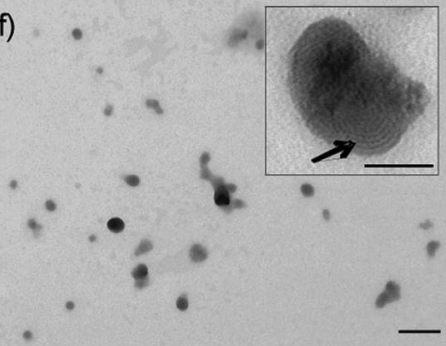

Fig. 3 Transmission electron microscopy of LPRs prepared using DOTMA:DOPE with the peptides (a) $\mathbf{K}_{6} \mathbf{B} 1-L 1-[Y]$, (b) $\mathbf{R}_{6} \mathbf{B} 1-\mathrm{L} 1-[Y]$, (c) $\mathbf{H}_{6} \mathbf{B} 1-\mathrm{L} 1-[Y]$, (d) $\mathrm{K}_{12} \mathrm{BO}-\mathrm{L} 1-[\mathrm{Y}]$ and (e) $\mathrm{K}_{6} \mathrm{~B} 2-\mathrm{L} 1-[\mathrm{Y}]$ at a $0.5: 6: 1 \mathrm{LPR}$ charge ratio and (f) DOTMA:DOPE:siRNA LR complexes at a 0.5:1 charge ratio. The siRNA concentration in all samples was $0.05 \mathrm{mg} \mathrm{mL}^{-1}$. Size bar represents $200 \mathrm{~nm}$ on original images and $50 \mathrm{~nm}$ on inserts. 
in DNA lipoplexes. ${ }^{26}$ This lamellar structure was not observed in any of the LPR formulations, suggesting that the structure of LPRs is indeed very different from that of binary complexes composed of either PR or LR components alone.

Gel retardation assays and PicoGreen fluorescence studies in the absence of serum

The gel electrophoresis studies indicated that the peptides, regardless of whether formulated as a LPR or PR, complexed siRNA to a significant degree at both of the charges ratios studied (Fig. 4, Lane 1). The only exceptions were the complexes containing $\mathbf{K}_{\mathbf{1 2}} \mathbf{B 0}$-L1-[Y], $\mathbf{R}_{\mathbf{1 2}} \mathbf{B 0}-\mathbf{L 1}-[\mathbf{Y}]$ and the Group 3 peptides $(\mathbf{H H K})_{4}$ B1-L1-[Y], $\left(\mathbf{K H}_{3}\right)_{4}$ B1-L1-[Y] and $\left(\mathbf{H}_{3} \mathbf{K}\right)_{4}$ B1-L1-[Y], where the siRNA was more completely complexed at the higher peptide charge ratio of $0.5: 12: 1$ for LPRs and 12:1 for PRs. In addition, incomplete siRNA complexation was observed with the histidine containing peptides, $\mathbf{H}_{6} \mathbf{B 1}-\mathbf{L 1}-[\mathbf{Y}], \mathbf{H}_{6} \mathbf{B 1}-\mathbf{L} 2-[\mathbf{Y}]$ and $\left(\mathbf{H}_{4} \mathbf{K}\right)_{3} \mathbf{B 1}-\mathbf{L 1}-[\mathbf{Y}]$ at both peptide charge ratios studied. Treatment of the LPRs and PRs with pAsp resulted in the expected dissociation of siRNA from the complexes (Fig. 4, Lane 2). Significantly LPRs and PRs treated with RNAse A followed by RNAse inhibitor and pAsp (Fig. 4, Lane 3) in order to assess the stability of the complexed siRNA to enzymatic degradation, suggested that all the complexes significantly protected siRNA from RNAse (Fig. 4, Lane 3), while naked siRNA was completely degraded by RNAse A under the same circumstances (Fig. 4, Lane B).

PicoGreen fluorescence studies were performed to further study the effectiveness of the packaging of siRNA within the LPR complexes (Fig. 5). Accessibility of PicoGreen to siRNA results in a reduction of its fluorescence intensity. In agreement with the gel retardation studies, a drastic reduction in fluorescence intensity was seen upon increasing the peptide content in the LPR complexes, reaching a plateau (suggesting that maximum complexation had been reached for that complex) at LPR charge ratios of between $0.5: 2: 1$ and $0.5: 18: 1$, the exact ratio depending upon the peptide used. For most complexes the plateau (or maximum complexation) was reached at LPR charge

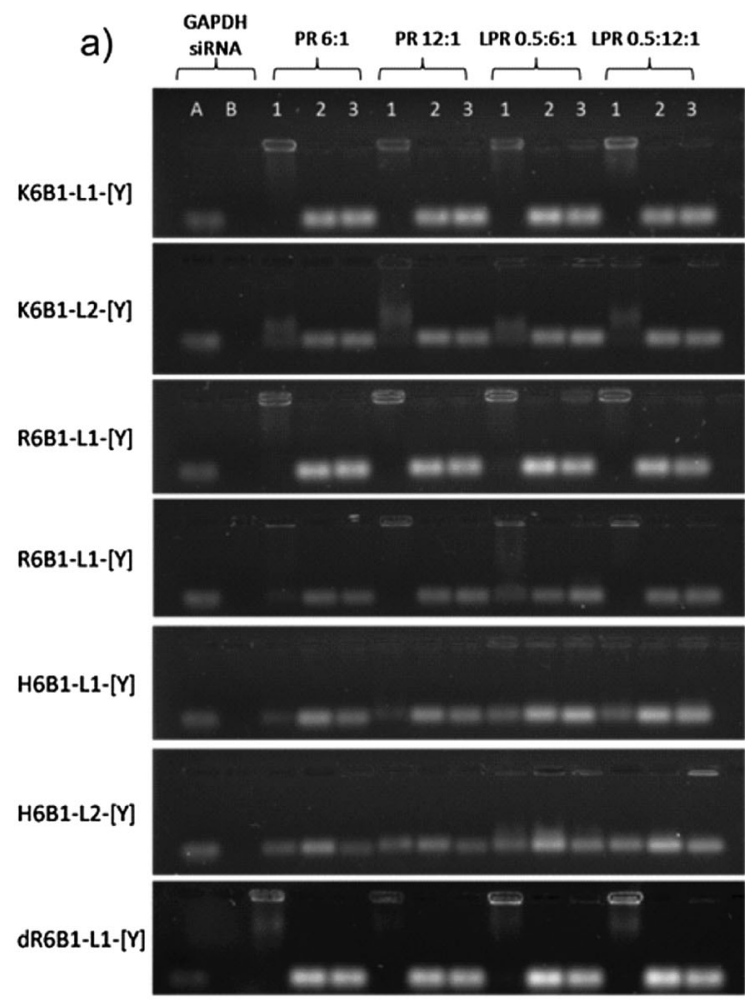

$\left(\mathrm{H}_{4} \mathrm{~K}\right)_{3} \mathrm{~B} 1-\mathrm{L} 1-[\mathrm{Y}]$ b)

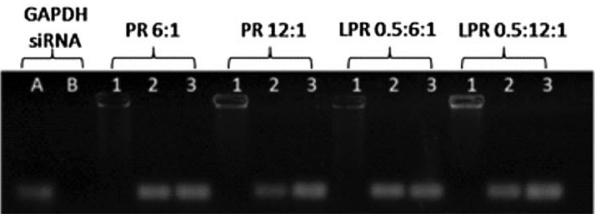

K6B2-L1-[Y]

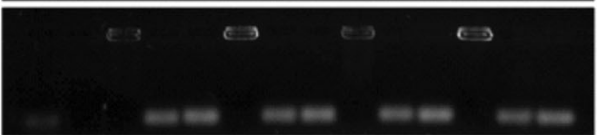

K6BO-L1-[Y]

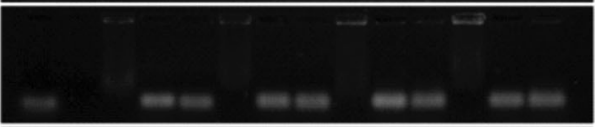

K12B0-L1-[Y]

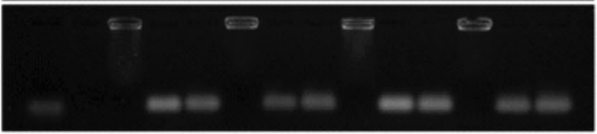

c)

\section{GAPDH}

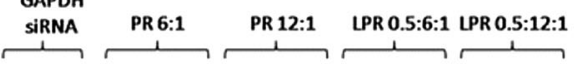

(HHK) ${ }_{4}$ B1-L1-[Y]

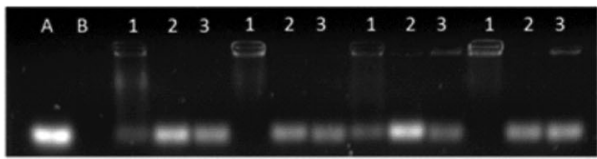

$\left(\mathrm{KH}_{3}\right)_{4} \mathrm{~B} 1-\mathrm{L} 1-[\mathrm{Y}]$

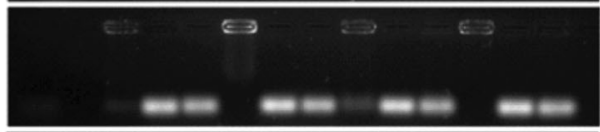

$\left(\mathrm{H}_{3} \mathrm{~K}\right)_{4} \mathrm{~B} 1-\mathrm{L} 1-[\mathrm{Y}]$
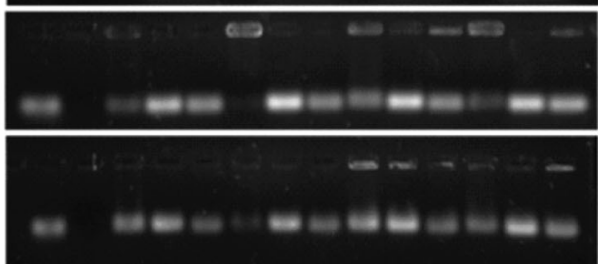

Fig. 4 Gel electrophoresis of LPR and PR complexes containing (a) Group 1, (b) Group 2 and (c) Group 3 peptides. LPR complexes were prepared with a charge ratio of lipid : peptide : siRNA of $0.5: 6: 1$ and $0.5: 12: 1$ while PR complexes were prepared with a charge ratio of peptide : siRNA of $6: 1$ and $12: 1$. The effect of the peptide component on siRNA complexation, protection from degradation by RNAse A and on siRNA release is labelled by Lanes 1 , 2 , and 3 respectively. Lane 1: untreated complexes. Lane 2: complexes treated with RNAse A followed by pAsp. Lane 3: complexes treated with pAsp only. Lane A: siRNA control. Lane B: siRNA treated with RNAse A. 


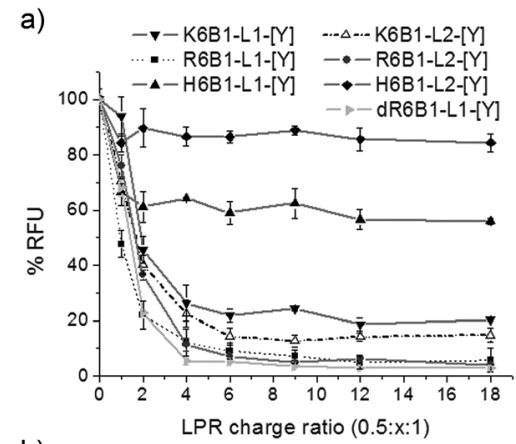

b)

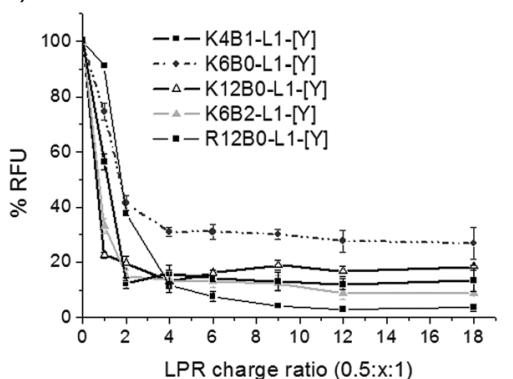

c)

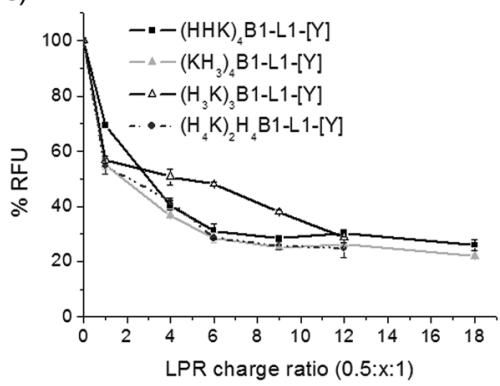

Fig. 5 Picogreen fluorescence binding assay showing siRNA packaging within LPR complexes using (a) Group 1, (b) Group 2 and (c) Group 3 peptides. LPR complexes were prepared with constant charge ratios of lipid and siRNA $(0.5: 1)$ and varying peptide charge ratios $(x=1-18)$. Relative fluorescence units (RFU) of the LPR complexes were calculated as percentage fluorescence from free siRNA. ratios of $0.5: 4: 1$, the exception being the complexes prepared using the Group 3 peptides, and in particular $\left(\mathbf{H}_{3} \mathbf{K}\right)_{4} \mathbf{B 1}-\mathbf{L 1}-[\mathbf{Y}]$, where a plateau was only reached at LPR charge ratios of $0.5: 12: 1$. In addition, the extent of complexation, indicated by the fluorescence intensity of the plateau region, was strongly influenced by the nature of the peptide used to prepare the complex. For example, only a small reduction in fluorescence intensity of 10 and $40 \%$ of the intensity of free siRNA was observed in LPRs formulated with the His-only containing peptides $\mathbf{H}_{6}$ B1-L1-[Y] and $\mathbf{H}_{6}$ B1-L2-[Y], respectively (Fig. 5a). This contrasted with a $\sim 70 \%$ reduction in fluorescence seen with complexes containing Group 3 peptides comprising both His and Lys residues. The maximum reduction in fluorescence intensity of $95 \%$ was achieved with complexes prepared using the Arg and Lys rich peptides, namely $\mathbf{R}_{\mathbf{6}} \mathbf{B 1}-\mathbf{L 1}-[\mathbf{Y}], \mathbf{R}_{\mathbf{6}} \mathbf{B 1}-\mathbf{L} 2-[\mathbf{Y}]$, $\mathbf{d R}_{6} \mathbf{B 1}-\mathbf{L 1}-[\mathbf{Y}]$ and $\mathbf{K}_{12}$ B0-L1-[Y] (Fig. 5a and c).

\section{Gel retardation assays in the presence of serum}

Further gel electrophoresis studies were performed (Fig. 6) to study the complexation and stability under various conditions of LPRs prepared using 6 selected peptides, namely $\mathbf{K}_{\mathbf{6}} \mathbf{B 1}-\mathbf{L 1}-[\mathbf{Y}]$, $\mathbf{R}_{6}$ B1-L1-[Y], $\quad \mathbf{H}_{6}$ B1-L1-[Y], $\quad \mathbf{K}_{12}$ B0-L1-[Y], $\quad \mathbf{K}_{6}$ B2-L1-[Y] and $\left(\mathbf{H}_{3} \mathbf{K}\right)_{\mathbf{4}} \mathbf{B 1}-\mathbf{L 1}-[\mathbf{Y}]$. These peptides were selected for further study as they represented a cross selection of the peptides studied, with some facilitating a good degree of knockdown in the presence of serum while others appeared to be ineffective. The LPRs were therefore prepared in a range of aqueous solvents, namely fully in water, or $12.5 \% \mathrm{v} / \mathrm{v}$ water diluted in $10 \%$ FBS solution, OptiMEM or serum-containing growth medium or alternately fully prepared in OptiMEM or fully in serum-containing media. It should be noted that the degradation of naked siRNA observed when dissolved in $10 \%$ FBS in water was undoubtedly due to the RNAses naturally present in serum. ${ }^{30}$ In contrast no degradation was observed when the siRNA was dissolved in water before addition to serumcontaining media (which also contains 10\% FBS) or (FBS-free) OptiMEM (Fig. 6, Lanes C and D). Furthermore, partial degradation of the siRNA was observed when it was prepared directly in serum-containing media. These results suggest that the action

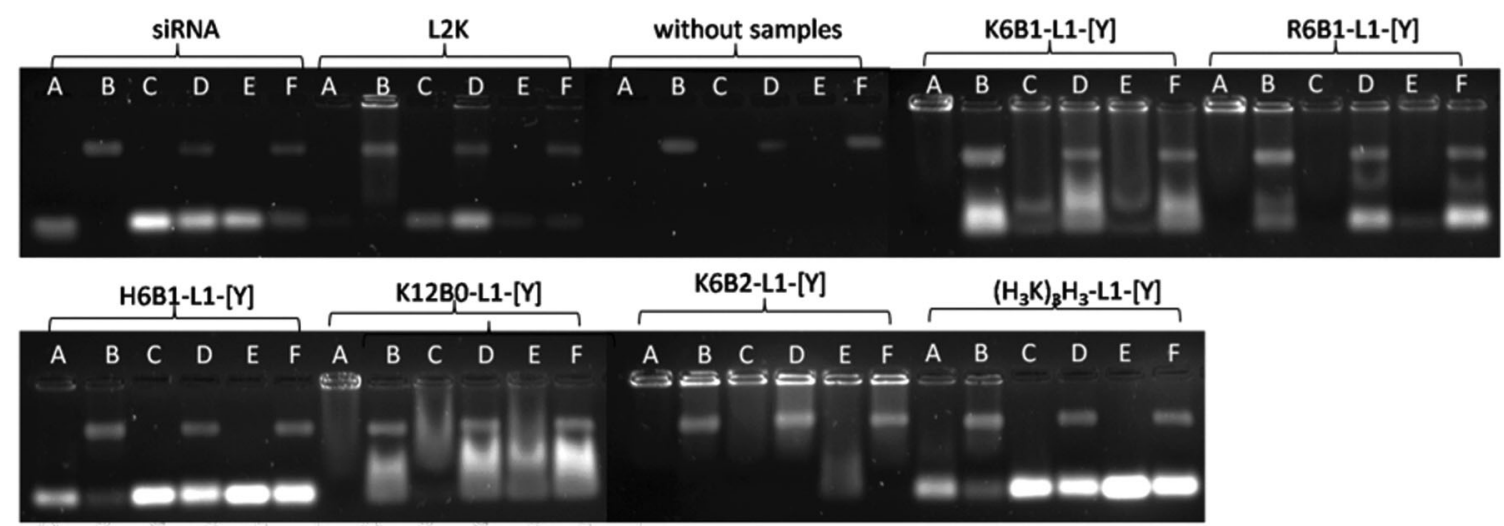

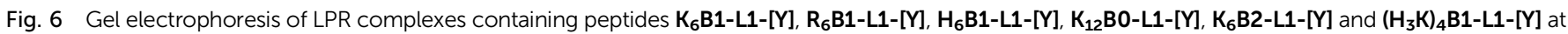
a $0.5: 6: 1$ charge ratio. Free siRNA and L2K : siRNA at $5: 1$ weight ratio were used as controls. Samples were prepared in (A) fully in water, (B) $12.5 \%$ v/V water diluted in $10 \% \mathrm{FBS}$, (C) $12.5 \% \mathrm{v} / \mathrm{v}$ water diluted in OptiMEM, (D) $12.5 \% \mathrm{v} / \mathrm{v}$ water diluted in media, (E) fully in OptiMEM and (F) fully in media and were incubated at $37{ }^{\circ} \mathrm{C}$ for 60 minutes prior to the gel electrophoresis experiment being performed. 
of RNAses present in serum might to some extent be inhibited by components present in media. It is not clear what component in the growth medium exerts this effect especially since RNAse free media was not used in the study. When serum containing media (no siRNA or LPR present) was examined by electrophoresis a new high molecular weight band was seen on the gel, which was thought to be due to fluorescence produced by the interaction of serum protein with GelRed nucleic acid stain. The presence of this band is not thought to interfere with the bands observed in the presence of siRNA or LPR.

For the purposes of comparison, the corresponding results obtained using LRs prepared using L2K are shown. Although L2K is shown to complex siRNA efficiently in water (Fig. 6, Lane A), some siRNA release (and possible degradation) is detected in the other conditions tested. Interestingly, LPRs were shown to complex and protect siRNA to different extents in the different conditions. When comparing the complexation achieved using the Lys, Arg and His only-containing peptides $-\mathbf{K}_{\mathbf{6}} \mathbf{B 1}-\mathbf{L 1}-[\mathbf{Y}], \mathbf{R}_{\mathbf{6}} \mathbf{B 1}-\mathbf{L 1}-[\mathbf{Y}]$ and $\mathbf{H}_{6} \mathbf{B 1}-\mathbf{L 1}-[\mathbf{Y}]$ - it is clear that the LPR containing $\mathbf{R}_{\mathbf{6}} \mathbf{B 1}-\mathbf{L 1}-[\mathbf{Y}]$ exhibited the highest degree of siRNA complexation when prepared in water and in OptiMEM with all the electrolytes it contains (Fig. 6, Lanes A, C and E) but only in the absence of serum (Fig. 6, Lanes B, D and F). In the case of $\mathbf{K}_{\mathbf{6}} \mathbf{B 1}-\mathbf{L 1}-[\mathbf{Y}]$, although well complexed in water, some dissociation of siRNA was observed in OptiMEM (Fig. 6, Lanes C, E) as well as in the serum containing aqueous solvents. As for $\mathbf{H}_{\mathbf{6}} \mathbf{B 1}-\mathbf{L 1}-[\mathbf{Y}]$, inefficient complexation was evident under all the conditions tested. Furthermore, some siRNA degradation was evident in the presence of $10 \%$ FBS as evidenced by the fainter siRNA (lower) band seen in Lane B. The Group 3 peptide, $\left(\mathbf{H}_{3} \mathbf{K}\right)_{\mathbf{4}} \mathbf{B 1}-\mathbf{L 1}-[\mathbf{Y}]$, behaved in a very similar manner to $\mathbf{H}_{6}$ B1-L1-[Y].

When comparing the effect of peptide branching, it was clear that although the linear peptide, $\mathbf{K}_{\mathbf{1 2}} \mathbf{B 0}$-L1-[Y] behaved in a very similar way to its singly branched counterpart, $\mathbf{K}_{\mathbf{6}} \mathbf{B 1}-\mathbf{L 1}-[\mathbf{Y}]$, the double branched $\mathbf{K}_{\mathbf{6}} \mathbf{B} \mathbf{2}-\mathbf{L} 1-[\mathbf{Y}]$ exhibited a significantly greater stability towards siRNA dissociation in the presence of both OptiMEM and serum, demonstrating an even higher degree of complexation than L2K. The reduced knockdown efficiency of the doubly branched peptide, $\mathbf{K}_{\mathbf{6}} \mathbf{B} 2-\mathbf{L} \mathbf{1}-[\mathbf{Y}]$, could therefore be a consequence of excessive binding that the peptide exerts on siRNA, possibly preventing the dissociation of siRNA within the cell.

\section{Circular dichroism studies}

Circular dichroism (CD) spectra of siRNA, 6 selected peptides

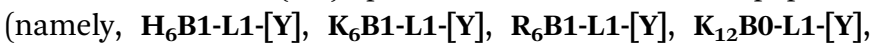
$\mathbf{K}_{6} \mathbf{B} 2-\mathbf{L 1}-[\mathrm{Y}]$ and $\left.\left(\mathrm{H}_{3} \mathbf{K}\right)_{4} \mathbf{B 1}-\mathbf{L 1}-[\mathrm{Y}]\right)$ and their respective PR, LPR and lipid:siRNA (LR) complexes at different charge ratios using DOTMA:DOPE vesicles were measured (Fig. 7 and Fig. S7, ESI $\dagger$ ). It should be noted that despite the relatively large size measured for some of the complexes, particularly the PRs, all preparations appeared clear, and showed very little evidence of light scattering, as assessed by simultaneous measurement of the UV spectroscopy of the samples (data not shown).

The CD spectra of individual LPR components were measured initially. Peptides alone dissolved in $\mathrm{D}_{2} \mathrm{O}$ exhibited a positive peak at $\sim 220 \mathrm{~nm}$ and a large negative signal at $\sim 200 \mathrm{~nm}$, indicative of the peptides adopting, in solution a polyproline II (PII) conformation characterized by a left-handed helical turn ${ }^{31}$ (Fig. 7a and b). Normalising the CD spectra according to the number of amide residues per mole of peptide (Fig. $7 \mathrm{~b}$ ) revealed that $\mathbf{K}_{\mathbf{6}} \mathbf{B 1}-\mathbf{L 1}-[\mathbf{Y}]$ exhibits the strongest PII conformation, while the rest of the peptides exist in equilibrium between PII and disordered state. siRNA alone was seen to adopt the characteristic A-form conformation with high positive and negative peaks at $260 \mathrm{~nm}$ and $210 \mathrm{~nm}$ respectively (Fig. S7, ESI $\dagger$ ). Any change in the intensity of the peaks at $260 \mathrm{~nm}$ and $210 \mathrm{~nm}$ respectively, indicates changes in base stacking $^{32}$ and/or the siRNA backbone structure, ${ }^{33}$ respectively. DOTMA:DOPE vesicles in $\mathrm{D}_{2} \mathrm{O}$ did not exhibit a CD spectrum at the range of concentrations tested.

To understand the nature of the ternary complexes, the binary complexes were first studied. Subsequently, the CD spectra of LRs were then measured to determine the siRNA conformation when complexed with DOTMA:DOPE at LR charge ratios of $0.5: 1-4: 1$, the lowest lipid ratio being similar to that used in LPR complexes. Spectra of LRs showed a reduction in the intensity of the positive peak at $\sim 260 \mathrm{~nm}$ and a deepening of the trough at $210 \mathrm{~nm}$ at all ratios tested when compared to the spectrum of free siRNA (Fig. S7e ESI $\dagger$ ). By subtracting the CD spectrum of free siRNA from that of the LR complexes, (and since DOTMA:DOPE itself does not exhibit a CD spectrum), any deviation in the shape of the subtracted CD spectra from baseline indicates a change in siRNA conformation (Fig. 7c).

The interaction of DOTMA:DOPE with siRNA is therefore thought to results in a change in base stacking of siRNA, as well as a change of siRNA backbone conformation. Interestingly, the reduction in band intensity at $260 \mathrm{~nm}$ in particular was not progressive upon increasing the lipid content, as previously observed in the case of lipid:DNA complexes, ${ }^{29}$ suggesting that a change in siRNA conformation was achieved at low $(0.5: 1)$ lipid : siRNA charge ratios, and the addition of further lipid did not cause any further conformational change in siRNA.

When examining the formation of PRs, the addition of peptide to siRNA did not cause significant changes in siRNA conformation, since the intensity of the positive band at $260 \mathrm{~nm}$ was preserved (Fig. S7b-f, ESI $\dagger$ ). When studying the ternary, LPR complexes, the band at $260 \mathrm{~nm}$ was similarly preserved, despite containing the same lipid content as that of an LR at 0.5:1 charge ratio, suggesting that the binding of the cationic peptides with siRNA takes precedence over the interaction of the lipid with siRNA.

In order to determine any changes in peptide conformation within a PR or an LPR complex, the CD spectrum of free siRNA was subtracted from those obtained for PR and LPR complexes and compared to the spectrum of their respective peptides in solution (Fig. 7d-i). Any difference suggests a conformational change in either the siRNA or the peptide in the complex. However, since the peptides do not exhibit any CD at wavelengths greater than $230 \mathrm{~nm}$, and very little change in the conformation of siRNA is observed in that region in both PR and LPR complexes, any changes in spectra below $230 \mathrm{~nm}$ were attributed to changes in peptide rather than siRNA conformation. 

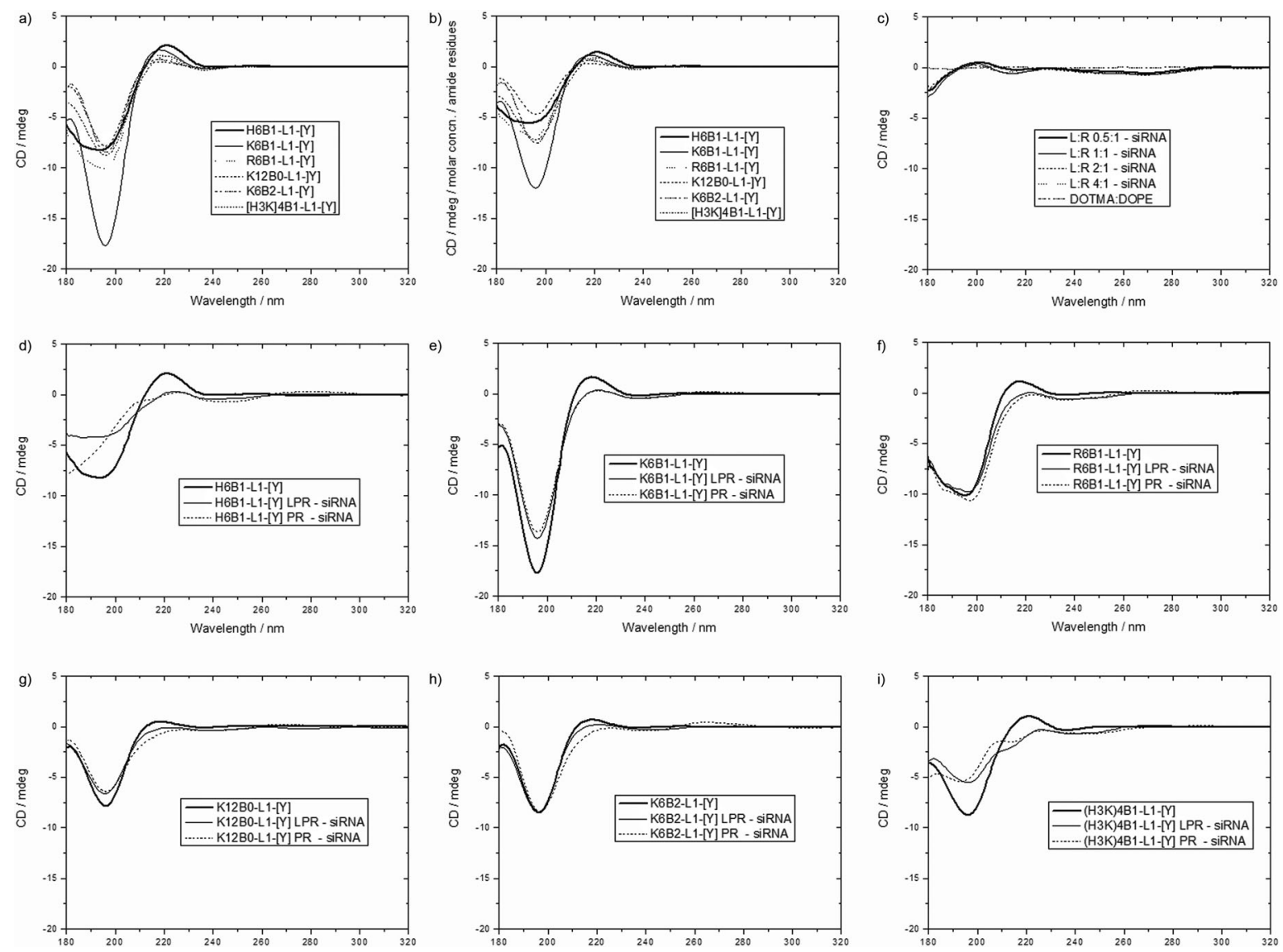

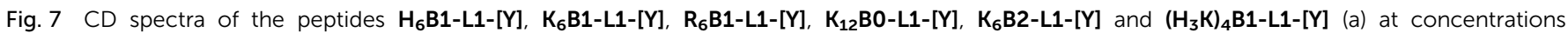
equivalent to those used in PR and LPR complexes and (b) normalised according to amide residues per peptide, (c) CD spectra of DOTMA:DOPE vesicles alone (black line) compared to LR complexes at various charge ratios minus the spectrum of siRNA at $4 \mu M$, (d-i) CD spectra of the above peptides alone (black line) at concentrations equivalent to those used in PR and LPR complexes, compared to the spectra of PR (light grey) and LPR complexes (dark grey) at $6: 1$ or $0.5: 6: 1$ charge ratios respectively, from which the spectrum of free siRNA at $4 \mu M$ is subtracted to show differences in siRNA or peptide conformation.

Differences in peptide conformation are shown through a reduction in the intensity of the peaks and troughs at $220 \mathrm{~nm}$ and $200 \mathrm{~nm}$ respectively (Fig. $7 \mathrm{~d}-\mathrm{i}$ ). Interestingly the most prominent differences are observed in peptides $\mathbf{H}_{6} \mathbf{B 1}-\mathbf{L 1}-[\mathbf{Y}]$, $\mathbf{K}_{6} \mathbf{B 1}-\mathbf{L 1}-[\mathbf{Y}]$ and $\left(\mathbf{H}_{3} \mathbf{K}\right)_{4} \mathbf{B 1}-\mathbf{L 1}-[\mathbf{Y}]$ (Fig. 7d, e and i), which have also shown the least siRNA binding capacity in gel electrophoresis and PicoGreen fluorescence studies. On the other hand, peptides $\mathbf{R}_{6} \mathbf{B 1}-\mathbf{L 1}-[\mathbf{Y}]$ and $\mathbf{K}_{6} \mathbf{B 2}-\mathbf{L 1}-[\mathbf{Y}]$, which were shown to bind siRNA the strongest, had preserved band intensities at $200 \mathrm{~nm}$. It is unclear, however, whether the preserved conformation of peptides $\mathbf{R}_{\mathbf{6}} \mathbf{B 1}-\mathbf{L 1}-[\mathbf{Y}]$ and $\mathbf{K}_{\mathbf{6}} \mathbf{B} \mathbf{2}-\mathbf{L 1}-[\mathbf{Y}]$ in the complexes enhances their ability to complex siRNA more effectively, thereby hindering siRNA dissociation within the cell. In this context it is worth noting that gel electrophoresis (Fig. 6) indicates that the dissociation of siRNA in the presence of electrolytes contained within OptiMEM and serum-containing media was lowest in these two peptides.

\section{Small angle neutron scattering}

The small angle neutron scattering (SANS) profiles were recorded for DOTMA: DOPE vesicles (1:1 molar ratio, at a final DOTMA concentration of $1 \mathrm{mg} \mathrm{mL}^{-1}$ in $\mathrm{D}_{2} \mathrm{O}$ ) and for LPR complexes formed from selected peptides at a charge ratio $0.5: 6: 1$, namely (b) $\mathbf{K}_{12}$, (c) $\left(\mathbf{H}_{3} \mathbf{K}\right)_{4} \mathbf{B 1}-\mathbf{L 1}-[\mathbf{Y}]$ and (d) $\mathbf{H}_{6}$ B1-L1-[Y] (Fig. 8). The corresponding data for LPRs containing peptides $\mathbf{R}_{\mathbf{6}} \mathbf{B 1}-\mathbf{L 1}-[\mathbf{Y}]$,

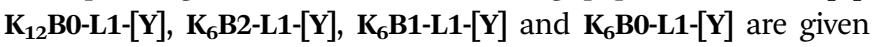
in Fig. S8, ESI. $\dagger$ Note that SANS experiments were not performed on the PRs due to their large size and high polydispersity coupled with the lack of any discernible internal structure in the complexes from TEM.

The variation in the intensity of the SANS as a function of $Q$ for cationic vesicles prepared using a 1:1 molar ratio of DOTMA and DOPE at a DOTMA concentration of $1 \mathrm{mg} \mathrm{mL}^{-1}$ in $\mathrm{D}_{2} \mathrm{O}$ (Fig. 8a) is in agreement with that obtained in our previous studies. ${ }^{29}$ Due to the relatively large average size of the cationic vesicles, the SANS data was modelled assuming either single flat sheets (i.e., unilamellar vesicles) or a combination of sheets and stacks (i.e., multilamellar vesicles). The modelling suggested the presence of vesicles that were predominantly unilamellar in nature, and that only a few multilamellar vesicles were present with about $3-4 \%$ of the lipid being in the form of multilamellar vesicles. This result correlates well with the relatively small 

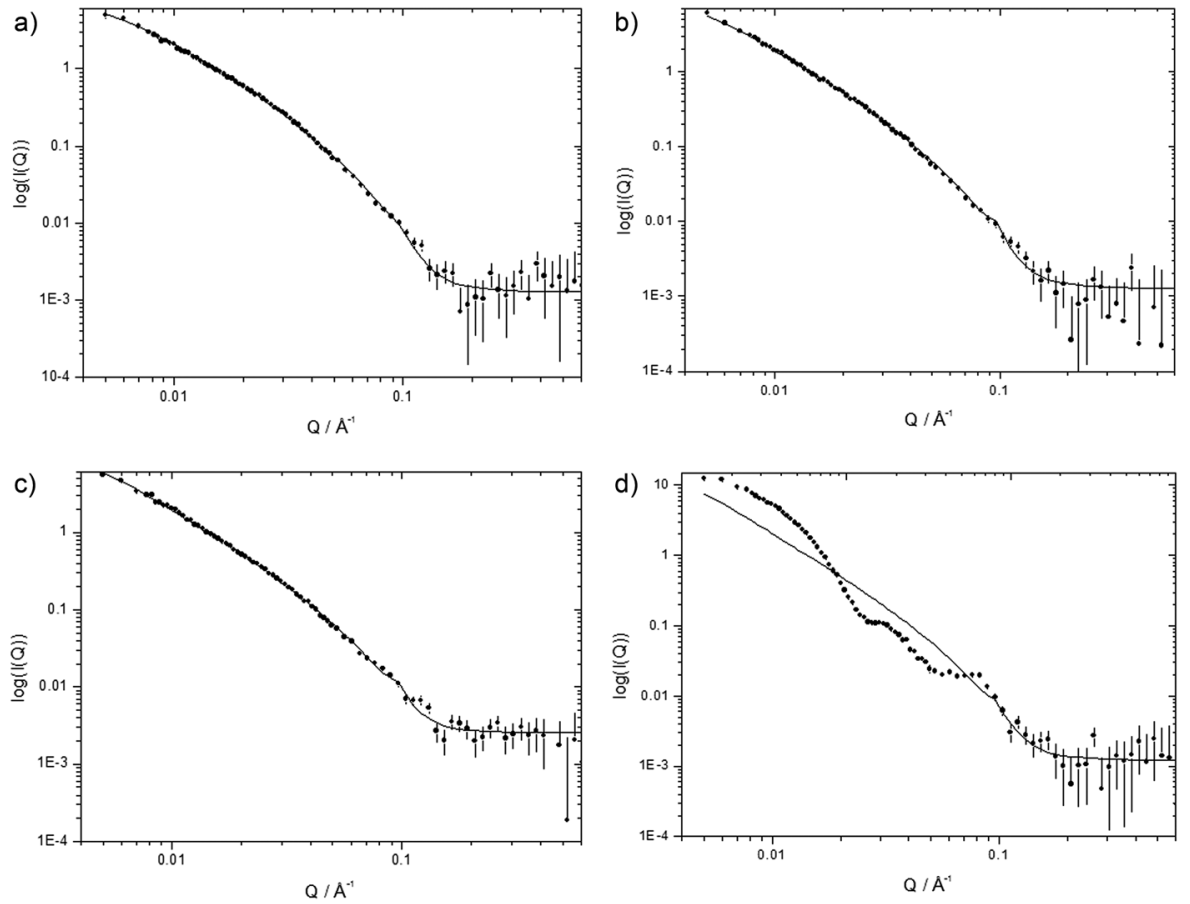

Fig. 8 Small angle neutron scattering data (dots) at $298 \mathrm{~K}$ and the best fit to the data (solid line) obtained using the mixed sheet and stack model for (a) cationic vesicles prepared from a 1:1 molar ratio of DOTMA:DOPE diluted to give the same DOTMA concentration as is present in the LPRs and LPRs containing (b) $\mathrm{K}_{12}$, (c) $\left(\mathrm{H}_{3} \mathrm{~K}\right)_{4} \mathrm{~B} 1-\mathrm{L} 1-[\mathrm{Y}]$ and (d) $\mathrm{H}_{6} \mathrm{~B} 1-\mathrm{L} 1-[\mathrm{Y}]$ at a $0.5: 6: 1$ charge ratio.

vesicle size measured by dynamic light scattering, which was indicative of the presence of very few multilamellar vesicles. The thickness and repeat distance (of $D$ spacing) of $41.5 \AA$ and $65 \AA$ reported in this study agree well with values of $44.7 \AA$ and $65 \AA$, previously reported for DOTMA:DOPE vesicles 1 1:1 molar ratio $)^{27}$ and with $39 \AA$ and $65 \AA$ reported for related DOTAP : DOPE vesicles (1:1 mola ratio). ${ }^{34,35}$ Furthermore, the use of a $R \sigma$ of $250 \AA$ to fit the data agrees well with that used in previous analysis of similar systems. ${ }^{27-29}$ Significantly, the DOTMA:DOPE vesicles examined using SANS were those used to prepare the LPR complexes.

SANS data for LPR complexes are shown in Fig. 8b-d and in Fig. S8, ESI. $\dagger$ With the exception of LPRs prepared using two peptides, namely $\mathbf{H}_{\mathbf{6}} \mathbf{B 1}-\mathbf{L 1}-[\mathbf{Y}]$ and $\mathbf{K}_{\mathbf{6}} \mathbf{B 0}-\mathbf{L 1}-[\mathbf{Y}]$ the scattering patterns recorded for the others LPRs are both qualitatively very similar to one another and to their parent DOTMA:DOPE vesicles. These scattering patterns suggest that the LPRs contain one or, in a small number of instances, more lipid bilayers. Furthermore, it was possible to fit the data obtained from all other LPRs, with the exception of those containing $\mathbf{K}_{\mathbf{6}} \mathbf{B} 2-\mathbf{L} 1-[\mathbf{Y}]$ and $\mathbf{K}_{\mathbf{6}} \mathbf{B 1}-\mathbf{L 1}-[\mathbf{Y}]$ using the same parameters as those used to fit the DOTMA:DOPE vesicles, suggesting that the bilayer present in the LPRs is by and large the same as in the vesicles. In order to fit the SANS data obtained for the LPRs containing peptides, $\mathbf{K}_{\mathbf{6}} \mathbf{B} \mathbf{2}-\mathbf{L} \mathbf{1}-[\mathbf{Y}]$ and $\mathbf{K}_{\mathbf{6}} \mathbf{B 1}-\mathbf{L 1}-[\mathbf{Y}]$ with comparable parameters to those obtained for the vesicle bilayers, it was necessary to use a higher $R \sigma$ of 380 and $520 \AA$ respectively, suggesting that the lipid bilayer in these LPRs is in a more rigid state. Unfortunately, due to the limited data sets available, it is not possible to unambiguously state that the bilayer in these LPRs is more rigid as, for example, it is also possible to these data sets using different parameters, such as a bilayer of different thickness. However, from a knowledge of the physico-chemical properties of the systems under consideration and the known rigidity of siRNA, it would be reasonable to assume that it is most likely that the rigidity of the lipid bilayer was increased.

The fact that it was possible to fit the data obtained from the LPRs using the same parameters as for the parent vesicles was in line with similar observations made on LPDs prepared using the same peptides ${ }^{29}$ and from cationic lipids containing unsaturated C14 chains. $^{27}$ In these LPDs it was assumed that the peptide and DNA complexed with each other and comprised the core of the lipid bilayer. There is no evidence from the SANS of the formation of multilayer structures produced from the interaction of cationic vesicles and siRNA. Furthermore, from inspection of the TEM data there is no evidence of the large, unstructured aggregates common for PDs. Hence, while it is not possible to unambiguously state if all the vesicles contain peptide/siRNA complexes, there is no evidence to suggest the presence of many, if any, empty vesicles.

Attempts to model the scattering patterns obtained from $\mathbf{H}_{6}$ B1-L1-[Y] and $\mathbf{K}_{6} \mathbf{B 0}$-L1-[Y] were unsuccessful as it appears that the preparation consists of mixtures of more than one type of aggregate. Unfortunately, there was insufficient experimental data to unambiguously determine the nature of the mixed aggregates. Indeed close inspection of the TEM data (Fig. 3c, LPRs prepared using $\mathbf{H}_{\mathbf{6}}$ B1-L1-[Y]) suggested the presence of only one type of aggregate. This observation was unexpected and is currently under investigation. 
In order to establish whether there was any internal structure inside the complexes, LPRs were prepared in $8.2 \mathrm{vol} \% \mathrm{D}_{2} \mathrm{O}$ in $\mathrm{H}_{2} \mathrm{O}$. This dispersion medium was specifically selected because the lipid was contrast matched to the medium and so therefore "invisible" to neutrons, and in this way it should be possible to determine both the size of any DNA and peptide "core" and to establish whether the peptide/DNA in the core possessed any regular structure. However, the concentration of the LPR complex used in the present study was too low to enable determination of either the size or the presence of any internal structure.

\section{Confocal fluorescence microscopy}

In order to assess the cellular uptake of the LPRs, confocal fluorescence microscopy studies were performed on A549-Luc cells transfected with LPRs formulated using six peptides, namely $\mathbf{K}_{6}$ B1-L1-[Y]， $\mathbf{R}_{6}$ B1-L1-[Y]， $\mathbf{H}_{6}$ B1-L1-[Y]， $\mathbf{K}_{12}$ BO-L1-[Y]， $\mathbf{K}_{6}$ B2-L1-[Y] and $\left(\mathbf{H}_{3} \mathbf{K}\right)_{4} \mathbf{B 1}-\mathbf{L 1}-[\mathbf{Y}]$. LPRs were prepared using RhodaminesiRNA (red) and BODIPY-lipid (green) and formulated in water then diluted with OptiMEM, and incubated with the cells for 4 hours. No significant differences in fluorescence distribution (Fig. 9a-f) were observed. In all the samples, the green fluorescence due to the lipid appears very punctate, suggesting it is incorporated within endosomal compartments. Although co-localisation of (green) lipid with (red) siRNA (seen as yellow) is seen in some cells in a number of the images, red siRNA is observed in the majority of cells, suggesting that the siRNA has predominantly dissociated from the lipid and possibly escaped
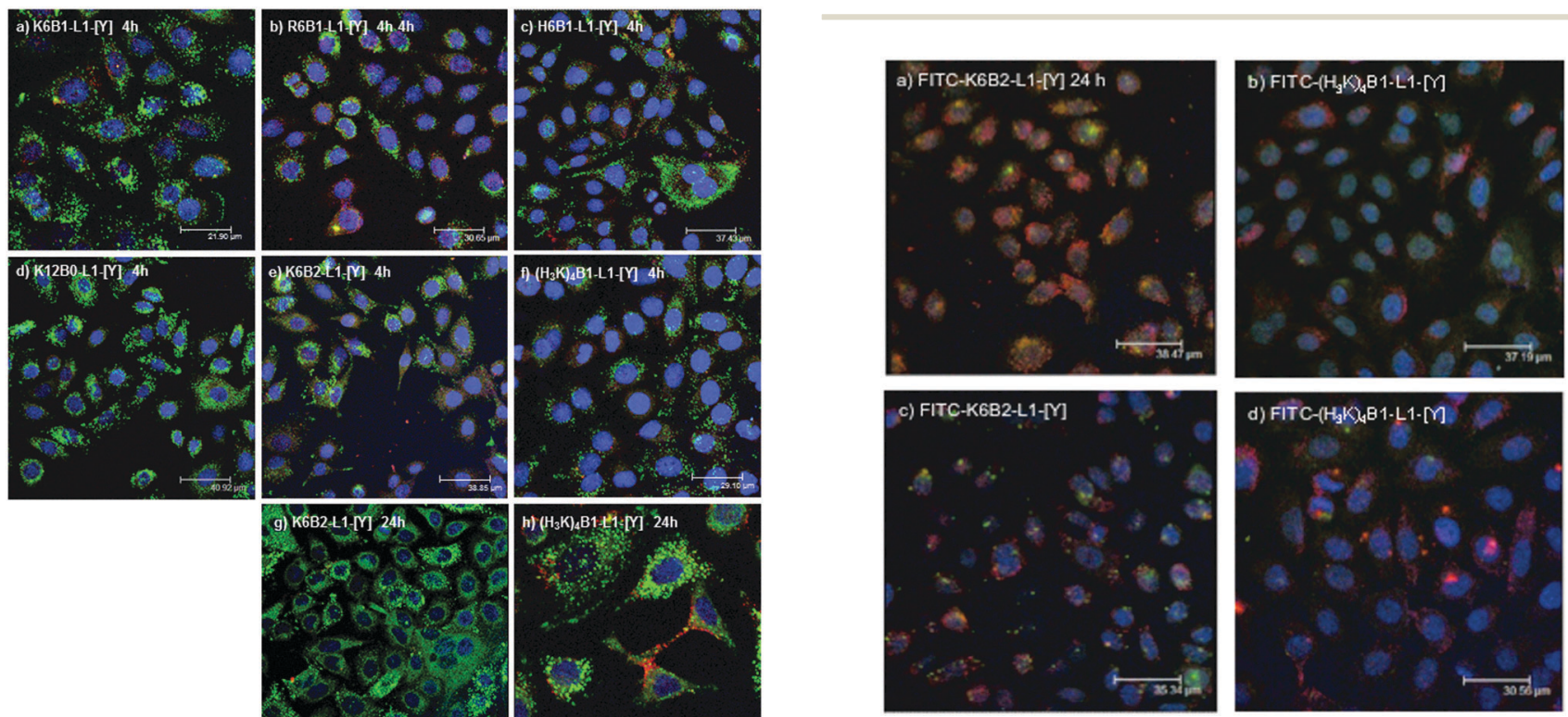

Fig. 10 Confocal microscopy of A549-luc cells transfected with LPR complexes prepared in $12.5 \%$ water then diluted in OptiMEM containing

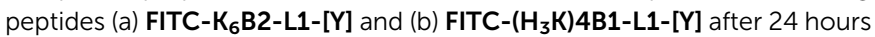
of incubation, or A549-luc cells transfected with LPR complexes prepared fully in OptiMEM containing peptides (c) FITC-K $\mathbf{K}_{6} \mathbf{B 2}-\mathbf{L} 1-[\mathrm{Y}]$ and (d) FITC( $\left.\mathrm{H}_{3} \mathrm{~K}\right) 4 \mathrm{B1}$-L1-[Y] after 24 hours of incubation. LPR complexes were prepared with FITC-labelled peptides (green, 100\%) and rhodamine labelled Silencer ${ }^{\circledR}$ Negative Control siRNA (red) at a lipid: peptide : siRNA charge ratio of $0.5: 6: 1$. The cell nucleus was stained with DAPI (blue) and the lipids were unlabelled. 
With the LPRs formulated from the peptide which showed the lowest knockdown activity, $\mathbf{K}_{\mathbf{6}} \mathbf{B} 2-\mathbf{L 1}-[\mathbf{Y}]$, after 24 hours the peptide and siRNA are still significantly co-localised (Fig. 10a and c). In contrast, with the LPRs formulated from the peptide with the highest knockdown activity, $\left(\mathbf{H}_{\mathbf{3}} \mathbf{K}\right)_{\mathbf{4}} \mathbf{B} 1-\mathbf{L 1}-[\mathbf{Y}]$, significant amounts of siRNA persist in the cytoplasm and are no longer co-localised with the peptide (Fig. 10b and d).

\section{Discussion}

The use of cationic peptide sequences in PR and LPR formulations for the delivery of siRNA has previously been studied by a number of groups. ${ }^{6-17}$ However, each previous study has tended to focus on one specific type of cationic residues, whereas in this study we aimed to compare the effects on complex structure and knockdown efficiency of complexes formed from Lys, Arg, His, D-Arg, and mixed Lys/His sequences.

Using the cell line studied in this paper, virtually all peptides gave impressive knockdown results when formulated into LPR complexes in water and diluted in OptiMEM (Fig. 2(a-c)). Under these conditions, even peptides lacking a targeting sequence, or with the cell targeting sequence scrambled, performed well. However, under physiologically relevant conditions, in which the LPR formulations were diluted in serum-containing growth media, major differences in knockdown efficiency resulted when both peptide sequence and formulation conditions were varied (Fig. 2(d-f) and Fig. S1, ESI $\dagger$ ). Firstly, LPR formulations prepared in water and diluted in growth media showed uniformly poor knockdown efficiencies, whereas certain LPR formulations prepared in OptiMEM and diluted in growth media retained good knockdown activities. As the main difference between the composition of OptiMEM and growth media is the presence of serum, this observation suggests that, although there was no difference in the knockdown achieved in the absence of serum, that the ions present in OptiMEM influenced the structure of the LPRs in a beneficial way with respect to their interaction with serum.

The formulations which retained the greatest knockdown activity when prepared in OptiMEM and diluted in growth media were those prepared using His-rich peptides. Thus those LPRs containing the Group 1 peptides, $\mathbf{H}_{6} \mathbf{B 1}-\mathbf{L 1}-[\mathbf{Y}]$ and $\mathbf{H}_{\mathbf{6}} \mathbf{B 1}-\mathbf{L} 2-[\mathbf{Y}]$ produced the greatest levels of knockdown, while those containing peptides possessing His-rich sequences from the Group 3 peptides gave good to excellent knockdown. The sequences $\left(\mathbf{K H}_{3}\right)_{4} \mathbf{B 1}-\mathbf{L 1}-[\mathbf{Y}]$ and $\left(\mathbf{H}_{3} \mathbf{K}\right)_{4} \mathbf{B 1}-\mathbf{L 1}-[\mathbf{Y}]$, which were identified by Mixson ${ }^{13}$ as being most effective for siRNA delivery, also performed the best in our study. However, interestingly there was no major difference between LPRs formulated from these peptides, and LPRs formulated from the other His-rich sequences which were previously identified as being suboptimal for siRNA delivery. ${ }^{13}$ These observations suggest that the charge on the peptide plays an important role in the knockdown efficiency of the complexes in the presence of serum and that the partially charged histidine peptides were less affected by its presence than the more highly charged peptides. This point is further reinforced by the fact that LPRs prepared from the more highly charged peptides based on Lys or Arg sequences showed significantly better activities when the non-charged linker, GAGA, was used instead of RVRRGA (Fig. 2e). In comparison, in our previous work studying the effectiveness of these peptides in delivering DNA in LPD complexes, the His-rich sequences showed very poor transfection efficiencies and the RVRRGA linker was also critical for good transfection. ${ }^{27}$ The present results suggest that the cleavage of the peptide by furin within the endosome is not the crucial step for knockdown, but rather release of the siRNA from the complex in the cytoplasm is. This confirms the observations of other groups that the best delivery vehicles for DNA may not be optimal for siRNA delivery. ${ }^{1-4}$ It should also be noted that, whilst the best knockdown efficiencies in growth media were obtained with LR complexes prepared using L2K (Fig. 2d-f) these complexes also exhibited the lowest cell viability (Fig. S3, ESI $\dagger$ ), whereas the LPRs studied had over $80 \%$ viability compared to controls.

In order to understand more fully the reasons for these observations, we carried out a series of biophysical studies comparing the LPR complexes. PicoGreen fluorescence studies, and gel shift assays in both the absence and presence of serum, indicated that the majority of the peptides packaged siRNA in tightly bound complexes, and that the siRNA packaging efficiency of the complexes was not improved by using more highly branched peptides. However, the LPR complexes which showed the best knockdown in the presence of serum - the His-rich Group 3 peptides and the Group 1 peptides $\mathbf{H}_{6} \mathbf{B 1}-\mathbf{L 1}-[\mathbf{Y}]$ and $\mathbf{H}_{6} \mathbf{B 1}-\mathbf{L} 2-[\mathbf{Y}]$ - showed reduced siRNA complexation and protection from siRNA degradation. As siRNA must be released into the cytoplasm in order to exert its knockdown effect, this in turn suggests that incomplete complexation of the siRNA and therefore more effective release from the nanocomplex is key to the greater knockdown efficiencies of these LPR complexes.

We next compared the effects of LPR complex formulation with the different peptides on the structural properties of these nanocomplexes. Whilst the sizes of the LPR complexes were all very similar, regardless of the peptide used, LPRs prepared with the His- or His-rich peptides had a lower surface charge (Fig. S5, ESI $\dagger$ ), probably due to the lower charges on these peptides at neutral $\mathrm{pH}$. TEM imaging of the LPR complexes showed them to be small, homogeneous and electron dense with no internal structure visible. By comparison, some LPD nanocomplexes formulated with these peptides had ordered core structures $^{29}$ again emphasising the key differences between DNA and siRNA carriers. CD studies indicated that in contrast to LPDs, where the conformation of DNA in the complex was generally found to be different to that free in solution, ${ }^{29}$ the conformation of siRNA was unaltered when in the form of an LPR. Furthermore, CD studies showed that the His- and His-rich peptides, $\mathbf{H}_{\mathbf{6}} \mathbf{B 1}-\mathbf{L 1}-[\mathbf{Y}]$ and $\left(\mathbf{H}_{\mathbf{3}} \mathbf{K}\right)_{\mathbf{4}} \mathbf{B 1}-\mathbf{L 1}-[\mathbf{Y}]$ exhibited the greatest change in their spectra when in the form of an LPR while the peptides, $\mathbf{R}_{\mathbf{6}} \mathbf{B 1}-\mathbf{L 1}-[\mathbf{Y}]$ and $\mathbf{K}_{\mathbf{6}} \mathbf{B} 2-\mathbf{L 1}-[\mathbf{Y}]$, which were shown by PicoGreen fluorescence studies and gel shift assays to bind siRNA to the greatest extent, preserved their spectra. This suggests that in order to complex the siRNA, the His and His-rich peptides have 
to undergo an amount of structural change, possibly explaining the greater tendency of the complexes containing these peptides to dissociate.

For the majority of peptides, including the His-rich peptide, $\left(\mathbf{H}_{3} \mathbf{K}\right)_{4} \mathbf{B 1}-\mathbf{L 1}-[\mathrm{Y}]$, SANS studies indicated that the LPRs contained a lipid bilayer that possessed virtually identical physico-chemical properties to the bilayer of the parent vesicles from which they were formed. Similar results were previously found for LPDs prepared from the same peptides as studied here. ${ }^{29}$ Interestingly however, the bilayer present in the LPRs containing $\mathbf{K}_{6} \mathbf{B 2}$-L1-[Y] and $\mathbf{K}_{6} \mathbf{B 1}-\mathbf{L 1}-[\mathbf{Y}]$ although of a similar thickness is thought to be slightly more rigid than in the parent vesicle. It is not known what effect the slightly more rigid bilayer may have on the transfection ability of the LPRs. Furthermore, for reasons as yet unknown, it was not possible to model the SANS data obtained for LPRs containing $\mathbf{H}_{6} \mathbf{B 1}-\mathbf{L 1}-[\mathbf{Y}]$ and $\mathbf{K}_{6} \mathbf{B 0}-\mathbf{L 1}-[\mathbf{Y}]$ suggesting the presence of a mixture of aggregates.

What effects do these difference in complexation efficiency, surface charge and internal structure have on the fate of the components once the LPR particles have entered the cell? Confocal studies on LPR particles formulated either in water/ diluted in OptiMEM, or formulated in OptiMEM/diluted in OptiMEM, were carried out with the lipid, siRNA and peptide components variously labelled. When using LPRs prepared with labelled lipid and siRNA, it was clear that in all cases the lipid had largely dissociated from the LPR complex after 4 hours, regardless of the peptide sequence, and appeared to be distributed within endosomal compartments. Similarly, the siRNA is seen to have dissociated from the lipid and is distributed throughout the cells, rather than remaining in the endosomal compartment or being trafficked to the nucleus. We have previously shown for LPD complexes that endosomal release of the components is most likely mediated by the helper lipid DOPE, with the "proton sponge" effect of the cationic peptides in the formulations having only a negligible effect. ${ }^{27}$ However, the most effective LPR formulations, using either $\left(\mathbf{H}_{3} \mathbf{K}\right)_{4} \mathbf{B 1}-\mathbf{L 1}-[\mathrm{Y}]$ or $\mathbf{H}_{6} \mathbf{B 1}-\mathrm{L1}-[\mathrm{Y}]$, showed larger amounts of siRNA within the cells and that this higher level of siRNA persisted, at least up to $24 \mathrm{~h}$ after incubation (Fig. 9h and Fig. S8d, ESI $\dagger$ ). Further confocal experiments using labelled H$_{6}$ B1-L1-[Y] supported the observation that siRNA after 24 hours incubation was in the cytoplasm of the cell and showed that the siRNA was no longer co-localised with the peptide (Fig. 10b and d). By contrast, using labelled lipid and siRNA indicated that little siRNA was observed in cells treated with LPRs formulated using the peptide with the lowest knockdown activity but the tightest siRNA binding, $\mathbf{K}_{\mathbf{6}} \mathbf{B 1}-\mathbf{L 1}-[\mathbf{Y}]$. Furthermore, when studying LPRs formulated using labelled $\mathbf{K}_{6} \mathbf{B 2}-\mathbf{L 1}-[\mathbf{Y}]$ and siRNA showed that the labelled peptide was significantly co-localised with siRNA after 24 hours (Fig. 10a and c).

\section{Conclusions}

We have carried out a comprehensive comparative study of the siRNA delivery and gene knockdown properties of nanoparticles formulated from different cationic peptide sequences, a 1:1 mixture of the lipids DOTMA and DOPE, and siRNA. We have compared polyplex (PR) and lipopolyplex (LPR) formulations and have demonstrated that the LPR formulations have significantly better gene knockdown under a range of conditions. In the cell line studied, and in these ternary complexes, branched peptides containing His or mixed His-Lys sequences are the most effective, particularly when knockdown experiments are carried out in physiologically relevant growth media. Furthermore, these lipopolyplex formulations were much less toxic than those prepared using the current "standard" reagent, L2K.

In order to understand the molecular basis for these findings, we have studied the biophysical properties of these nanocomplexes in detail. We have shown that the looser binding of the mixed His/Lys peptides to their siRNA cargo is key to their higher knockdown efficiencies, and that this is an effect arising from both lower peptide charge at $\mathrm{pH} 7$ and a different geometry of interaction between peptide and siRNA. These in turn lead to nanoparticles in which the siRNA is more efficiently delivered and persists for longer in the cells. Importantly, we have also shown that the conditions under which the LPR complexes are formulated are critical to the knockdown efficiencies in serum, with nanocomplexes formulated in OptiMEM and subsequently diluted in serum being most effective. Whilst OptiMEM would not be regarded as a suitable formulation solvent for clinical studies, where well defined, simple electrolyte solvents are preferred, these results suggest that formulating LPR complexes under conditions of higher salt would be beneficial for delivery of siRNA under physiologically relevant conditions. Further studies in this area are currently in progress and will be reported in due course.

\section{Experimental procedures}

\section{Materials}

The synthesis of the bifunctional peptides used in the present study has been previously described. ${ }^{29}$ Characterisation data for the control (scrambled) peptide sequence, $\mathbf{s K}_{6} \mathbf{B 1}-\mathbf{L 1}-[\mathbf{Y}]$ is given in the ESI. $\dagger$ The methods used for the FITC labelling of selected peptides (namely $\mathbf{K}_{6} \mathbf{B 2}-\mathbf{L 1}-[\mathbf{Y}]$ and $\left(\mathbf{H}_{3} \mathbf{K}\right)_{4} \mathbf{B 1}-\mathbf{L 1}-[\mathbf{Y}]$ ) are detailed in the ESI. $\dagger$ Silencer ${ }^{\circledR}$ Firefly Luciferase (GL2 + GL3) (Luc-siRNA) and Silencer ${ }^{\mathbb{R}}$ Negative Control siRNA \#1 were purchased from Ambion (USA). A custom-made siRNA sequence, CUU ACG CUG AGU ACU UCG dTdT, termed here Sigma siRNA was purchased from Sigma-Aldrich (UK) and used for samples requiring high amounts of siRNA, namely small angle neutron scattering (SANS), dynamic light scattering, zeta potential and circular dichroism (CD) measurements. Uranyl acetate, agarose, RNAse A, RNAse inhibitor, poly-L-aspartic acid (pAsp) and all cell culture growth media and other reagents including 1,4-diazabicyclo[2.2.2] octane (DABCO) were purchased from from Sigma (UK), unless otherwise stated. 4',6-Diamidino-2phenylindole dihydrochloride (DAPI) and Pierce BCA Protein Assay kit were was purchased from Thermo Scientific (UK). OptiMEM, Lipofectamine 2000 (L2K), PicoGreen reagent and 
2-(4,4-difluoro-5-methyl-4-bora-3a,4a-diaza-s-indacene-3-dodecanoyl)1-hexadecanoyl-sn-glycero-3-phosphocholine ( $\beta$-BODIPY ${ }^{\circledR}$ 500/510 C12-HPC) (BODIPY-HPC) were purchased from Invitrogen Molecular probes, UK. Label-IT ${ }^{\circledR}$ TM-Rhodamine siRNA Tracker Intracellular Localization Kit was supplied by Mirus (USA). GelRed nucleic acid stain was obtained from Cambridge Bioscience (UK). $N$-[1-(2,3-dioleyloxy)propyl]- $N, N, N$-trimethylammonium chloride (DOTMA) was obtained from TCI Europe, Belgium, and dioleylphosphatidylethanolamine (DOPE) was obtained from Avanti Polar lipids, Alabama, Alabaster, USA. GelRed was purchased from Gencompare, Belgiun and Luciferase assay kit was purchased from Promega (UK). Human alveolar A549-Luc cells, stably transfected with an episomal S/MAR luciferase vector as described by Argyros et al. ${ }^{36}$ were a gift from Dr M. T. Thanou (Institute of Pharmaceutical Science, King's College London, UK). All reagents were of the highest grade possible and were used without further purification. Double distilled, filtered water was used throughout. $\mathrm{D}_{2} \mathrm{O}$ (>99\% purity) was obtained from Aldrich (UK).

\section{Preparation of liposomes and stock solutions}

Cationic lipid vesicles composed of DOTMA:DOPE at 1:1 molar ratio were prepared as previously described. ${ }^{29}$ Briefly a thin film of lipid, obtained by evaporating chloroform from a lipidic chloroform solution, was hydrated with sufficient filtered, double distilled water to produce a DOTMA concentration of $1 \mathrm{mg} \mathrm{mL}{ }^{-1}$. The resulting crude lipid suspension was then probe sonicated (using a Lucas Dawes probe sonicator operating at 50\% output for 10 minutes at room temperature) to produce small unilamellar vesicles of $\sim 60 \mathrm{~nm}$ in diameter.

Peptide solution ( $1 \mathrm{mg} \mathrm{mL} \mathrm{mL}^{-1}$ ), siRNA solution and vesicle suspensions were diluted, as required, using either double distilled, filtered water (for dynamic light scattering, zeta potential, gel shift assays and TEM) or $\mathrm{D}_{2} \mathrm{O}$ (for CD and SANS), or in the case of knockdown studies, water or OptiMEM to give the required siRNA and peptide stock solutions, and the lipid stock suspensions for the preparation of PR and LPR complexes.

\section{Formation of PR and LPR}

Polyplexes (complexes of Peptide and siRNA, PR complexes) were formulated by adding equal volumes of the required siRNA stock solution to a peptide solution containing sufficient peptide to produce PRs at either a 6:1 or 12:1 (nominal) charge ratio, i.e. assuming all peptides are fully ionised under the conditions of use. The concentrations used depending on the nature of the experiment to be performed.

Lipopolyplexes (complexes of Lipid, Peptide and siRNA, LPR complexes) were prepared at LPR (nominal) charge ratios of 0.5:6:1 and 0.5:12:1 (i.e. assuming all peptides are fully ionised under the conditions of use) by first mixing equal volumes of cationic vesicles suspension and peptide solution and then adding with thorough mixing an equal volume of siRNA solution. For example, for the in vitro cell studies, $75 \mu \mathrm{L}$ of a peptide solution (at the required concentration) was added to $75 \mu \mathrm{L}$ DOTMA:DOPE vesicle suspension (containing $5.7 \mu \mathrm{g} \mathrm{mL}^{-1}$ of DOTMA). To this lipid:peptide mixture, an equal volume of siRNA solution (i.e. $150 \mu \mathrm{L}$ of a $2.7 \mu \mathrm{g} \mathrm{mL}{ }^{-1}$ siRNA solution) was added and the LPDs prepared by the gentle shaking of the resulting suspension.

\section{Dynamic light scattering and zeta potential measurements}

The apparent hydrodynamic size and the zeta potential of the LPR and PR complexes were measured by dynamic light scattering at $25 \pm 0.1{ }^{\circ} \mathrm{C}$ using a Zetasizer Nano ZS (Malvern Instruments, UK). LPR and PR complexes were prepared in double distilled, filtered water at $\mathrm{L}: \mathrm{P}: \mathrm{R}$ charge ratios of $0.5: 6: 1$ and $0.5: 12: 1$ and $P: R$ charge ratios of $6: 1$ and $12: 1$ using Sigma siRNA (final siRNA concentration of $26 \mu \mathrm{g} \mathrm{mL}^{-1}$ for the DLS measurements and $2.9 \mu \mathrm{g} \mathrm{mL} \mathrm{mL}^{-1}$ for the zeta potential measurements). Three repeat measurements were made for each complex. In all cases the complexes exhibited polydispersities of less than 0.3 .

\section{Circular dichroism spectroscopy}

The circular dichroism (CD) and ultra violet (UV) spectra of siRNA, LPRs and PRs, dispersed in $\mathrm{D}_{2} \mathrm{O}$, were measured at $20 \pm 2{ }^{\circ} \mathrm{C}$ using a Chirascan Plus spectrometer (Applied Photophysics, UK) operated with a scan speed of $30 \mathrm{~nm} \mathrm{~min}{ }^{-1}$, a bandwidth of $1 \mathrm{~nm}$ and a time per point of $2 \mathrm{~s}$. Spectra were recorded between 320 and $180 \mathrm{~nm}$ using a $1 \mathrm{~mm}$ path length cell. CD and UV absorbance spectra were acquired simultaneously. All spectra were corrected for a $\mathrm{D}_{2} \mathrm{O}$ background, which was measured periodically throughout the experiment. The CD and UV spectra of siRNA were measured at a concentration $4 \mu \mathrm{M}\left(0.050 \mathrm{mg} \mathrm{mL}^{-1}\right)$. The spectra of the LPR and PR complexes were measured at charge ratios of $0.5: 6: 1$ and $6: 1$, and a siRNA concentration of $0.050 \mathrm{mg} \mathrm{mL}^{-1}$.

\section{Transmission electron microscopy}

LPR and PR complexes, prepared at charge ratios of $0.5: 6: 1$ and $6: 1$, respectively and a final siRNA concentration of 0.05 $\mathrm{mg} \mathrm{mL}^{-1}$, were examined using transmission electron microscopy (TEM) by negative staining with an aqueous solution of $4 \% \mathrm{w} / \mathrm{v}$ uranyl acetate. Briefly, a drop of sample was placed on a formvar 200 mesh copper grid for one minute before the excess liquid was removed using a wick of filter paper. A drop of uranyl acetate was then added to the grid for approximately five minutes after which time the grid was washed with an aqueous solution of $50 \% \mathrm{v} / \mathrm{v}$ ethanol. After drying the samples were visualized using an FEI TecnaiTM transmission electron microscope (USA).

\section{Small angle neutron scattering}

The small angle neutron scattering (SANS) of LPRs and DOTMA: DOPE vesicles was measured on the SANS2D and LoQ beamlines at the ISIS pulsed neutron source (ISIS Facility, the RutherfordAppleton Laboratories, Didcot, UK). Freshly prepared DOTMA: DOPE vesicles dispersed in $\mathrm{D}_{2} \mathrm{O}$ were measured at a DOTMA concentration of $1 \mathrm{mg} \mathrm{mL} \mathrm{m}^{-1}$. LPR complexes were similarly freshly prepared in either 8.2 vol\% $\mathrm{D}_{2} \mathrm{O}$ in $\mathrm{H}_{2} \mathrm{O}$ or $\mathrm{D}_{2} \mathrm{O}$ at a Sigma siRNA concentration of $0.1 \mathrm{mg} \mathrm{mL}^{-1}$ and a $\mathrm{L}: \mathrm{P}: \mathrm{R}$ charge ratio of $0.5: 6: 1$. The SANS of the LPRs and vesicles and the relevant solvents were measured in $2 \mathrm{~mm}$ path length circular silica cells at $25 \pm 0.1{ }^{\circ} \mathrm{C}$. Where possible, the SANS of the parent vesicles and the LPRs were measured on more than one occasion to ensure the 
reproducibility of the data. Dynamic light scattering measurements of the vesicles and LPRs prepared in $\mathrm{D}_{2} \mathrm{O}$ confirmed that their preparation did not alter the size of the resulting nanoparticles.

The SANS intensity, $I(Q)$, of the LPDs and vesicles as a function of the scattering vector, $Q=(4 \pi / \lambda) \sin (\theta / 2)$, where $\theta / 2$ is the scattering angle, was determined by normalising the scattering to the appropriate sample transmission after subtraction of the scattering from the relevant solvent also normalised to its corresponding transmission. The fitting of the SANS data always included flat background corrections to allow for any mismatch in the incoherent and inelastic scattering between the sample and the solvent, with the levels of the fitted background being checked to ensure that they were physically reasonable. The SANS data for the DOTMA:DOPE vesicles and LPR complexes dispersed in $\mathrm{D}_{2} \mathrm{O}$ were routinely modelled either assuming a mixture of (isolated/single) infinite planar (lamellar) sheets with or without one-dimensional paracrystals (stacks) to account for the presence in the sample of any multilamellar vesicles. When modelling the vesicles and LPR complexes dispersed in $\mathrm{D}_{2} \mathrm{O}$ as (single) lamellar sheets, the fits to the SANS data were obtained by the least-squares refinement of three parameters, namely $L, R \sigma$, and the absolute scale factor (together with the background, as described above), where $R \sigma$ is the Lorentz correction factor which provides information about the extent of rigidity/curvature of the lamellar sheets. Unless otherwise stated a $R \sigma$ of $250 \AA$ was used. In this study the polydispersity on the thickness of the bilayer $(\sigma(L) / L)$ was fixed at 0.1 . When stacks were added to the (single) lamellar sheet model, the fit to the SANS data was obtained by least-squares refinement of seven parameters, namely $R \sigma$, the mean bilayer thickness $(L)$, the number of bilayers in the stack $(\mathrm{M})$, their mean separation or $d$-spacing $(D)$, the width of the Gaussian distribution in the plane, $(\sigma(D) / D)$, and the absolute scale factors for the unilamellar and multilamellar vesicles. In the present study, $\sigma(L) / L$ was again fixed as 0.1 and $\sigma(D) / D$ at 0.05, with a $R \sigma$ of $250 \AA$ was used. In addition, when modeling the SANS data using a mixed population of sheets and stacks, $L$, $\sigma(L) / L$, and $R \sigma$ were constrained to be the same for the isolated/ single and stacked lamellae, a not unreasonable assumption. If no Bragg peak was seen in the SANS data, it was fitted using a stack with a maximum of 2 bilayers. In such cases the data was fitted using a higher number of bilayers comprising the stacks to ensure that it did not improve the quality of the fit obtained. For all models, the least-squares refinements were performed using the model-fitting routines provided in the FISH software.

\section{Gel band shift assay}

Gel electrophoresis experiments were performed to determine (a) the extent of siRNA complexation, (b) the dissociation of siRNA in the presence of pAsp and (c) the extent of siRNA protection from enzymatic degradation by RNAse A, when the siRNA was formulated as either an LPR or PR complex - either at a charge ratio of $0.5: 6: 1$ and $0.5: 12: 1$ for the LPRs and a charge ratios of $6: 1$ and $12: 1$ for the PRs. Complexes were prepared in a volume of $10 \mu \mathrm{L}$ and at a siRNA concentration of $0.01 \mu \mathrm{g} \mu \mathrm{L}^{-1}$ (i.e. $0.1 \mu \mathrm{g}$ siRNA per well). To determine the extent of siRNA complexation, LPR or PR complexes were used without further treatment. For siRNA release studies, $1.25 \mu \mathrm{L}$ of a $1 \mathrm{mg} \mathrm{mL} \mathrm{m}^{-1}$ aqueous pAsp solution was added to the complexes. Experiments to determine the level of siRNA protection afforded by the complexes from enzymatic degradation were prepared by adding an aqueous solution of RNAse A (0.4 $\mu \mathrm{L}, 0.1 \mathrm{mg} \mathrm{mL}^{-1}$ ), incubating the resultant mixture for $30 \mathrm{~min}$ at $37{ }^{\circ} \mathrm{C}$, then adding an aqueous solution of RNAse inhibitor $\left(0.4 \mu \mathrm{L}, 30-50000 \mathrm{U} \mathrm{mL}^{-1}\right)$ to stop the enzymatic reaction. The mixture was further incubated at room temperature for $10 \mathrm{~min}$ after which time an aqueous pAsp solution $\left(1.25 \mu \mathrm{L}, 1 \mathrm{mg} \mathrm{mL}^{-1}\right)$ was added to release any protected siRNA. To all prepared samples, $2 \mu \mathrm{L}$ of gel loading buffer $(0.25 \% \mathrm{w} / \mathrm{v}$ bromphenol blue and $40 \% \mathrm{w} / \mathrm{v}$ sucrose) was added prior to loading the samples onto a $2 \% \mathrm{w} / \mathrm{v}$ agarose gel in Tris/Borate/ EDTA (TBE) buffer containing $3 \mu \mathrm{L}$ of GelRed nucleic acid stain at $80 \mathrm{~V}$ for $45 \mathrm{~min}$ (Fisher Brand, Model HU12 electrophoreses chamber) and visualized under UV light using an Alphalmage EP MultiImage Light Cabinet (Alpha Innotech, South Africa).

\section{Effect of media on lipopolyplex complexation and stability}

Gel electrophoresis experiments were also used to determine the extent of siRNA complexation and stability in LPR complexes when prepared in different conditions. LPRs were prepared in a total volume of $10 \mu \mathrm{L}$ at charge ratios of $0.5: 6: 1$ and a siRNA concentration of $0.01 \mathrm{mg} \mathrm{mL}^{-1}$ using the peptides $\left(\mathbf{K}_{\mathbf{6}} \mathbf{B 1}-\mathbf{L 1}-[\mathbf{Y}]\right.$, $\mathbf{R}_{6}$ B1-L1-[Y], $\quad \mathbf{H}_{6}$ B1-L1-[Y], $\quad \mathbf{K}_{12}$ B0-L1-[Y], $\quad \mathbf{K}_{6}$ B2-L1-[Y] and $\left.\left(\mathbf{H}_{3} \mathbf{K}\right)_{4} \mathbf{B 1}-\mathbf{L 1}-[\mathbf{Y}]\right)$, either fully in water, OptiMEM, or in serumcontaining growth media. LPR complexes were also prepared initially in water (in $12.5 \%$ of the total volume) then diluted with OptiMEM, serum-containing growth media or $10 \%$ fetal bovine serum (FBS) in water. Free siRNA and complexes of L2K:siRNA prepared at a 5:1 weight ratio in different media conditions and $10 \mu \mathrm{L}$ of the media alone in the absence of samples were used as controls. After incubation of all the samples at $37{ }^{\circ} \mathrm{C}$ for 60 minutes, $2 \mu \mathrm{L}$ of loading buffer was added to each sample before being loaded onto the gel and visualised as described above.

\section{PicoGreen fluorescence experiments}

PicoGreen assays were performed in black 96-well plates. For each well, $50 \mu \mathrm{L}$ of PicoGreen reagent $(1: 150 \mathrm{v} / \mathrm{v}$ diluted with Tris-EDTA (TE) buffer, pH 7.4) was mixed with $50 \mu \mathrm{L}$ of $4 \mu \mathrm{g} \mathrm{mL}{ }^{-1}$ of negative control siRNA in TE buffer (giving a final siRNA content of $0.2 \mu \mathrm{g}$ per well). LPR complexes were then formulated by adding $100 \mu \mathrm{L}$ of the siRNA : PicoGreen mixture to a mixture of equal volumes $(25 \mu \mathrm{L}$ each) of the appropriate concentration of lipid and peptide. The final LPR ratios were prepared such that the lipid:siRNA ratio remained constant at $0.5: 1$, but the peptide:siRNA charge ratio was increased (to $18: 1$ ). Fluorescence was measured at $\lambda_{\mathrm{ex}} / \lambda_{\mathrm{em}}=480 / 520 \mathrm{~nm}$ using a Varian Cary Eclipse fluorescence plate spectrophotometer. In each experiment, naked negative control siRNA mixed with PicoGreen was regarded as $100 \%$ fluorescence and was used to normalize the PicoGreen signal detected from the complexes. 


\section{Cell culture}

A549-Luc cells were maintained in RPMI-1640 growth medium supplemented with $10 \% \mathrm{v} / \mathrm{v}$ fetal bovine serum (FBS), $1 \% \mathrm{v} / \mathrm{v}$ of $100 \times$ strength non-essential amino acids (NEAA), 1\% v/v penicillin/streptomycin solution $\left(10000 \mathrm{U} \mathrm{mL}^{-1} / 10 \mathrm{mg} \mathrm{mL}^{-1}\right)$ and $1 \% \mathrm{v} / \mathrm{v} \mathrm{L}$-glutamine $200 \mathrm{mM}$. All cells were maintained at $37{ }^{\circ} \mathrm{C}, 5 \% \mathrm{CO}_{2}$ and $90 \%$ relative humidity. The cells were passaged every three to four days when around $70 \%$ confluent using $0.25 \% \mathrm{w} / \mathrm{v}$ trypsin-EDTA solution.

\section{In vitro knockdown experiments}

L2K was used in all knockdown experiments as a positive control when mixed with siRNA at a L2K:siRNA weight ratio of $5: 1$. Free Luc-siRNA was used as a negative control. A549-Luc cells were seeded onto 96 -well plates at $1.2 \times 10^{4}$ cells per well and incubated for $24 \mathrm{~h}$ at $37{ }^{\circ} \mathrm{C}$ in a $5 \% \mathrm{CO}_{2}$ and $90 \%$ relative humidity.

The growth medium $(100 \mu \mathrm{L})$ in each well was then replaced with $50 \mu \mathrm{L}$ of either OptiMEM or fresh (serum-containing) growth medium followed by the addition of $50 \mu \mathrm{L}$ of the appropriate LPR complex at a charge ratio of either $0.5: 6: 1$ or $0.5: 12: 1$ or a PR complex at a charge ratio of $6: 1$. The effect of the ionic strength of the solvent used to prepare the complexes and the presence of serum on the knockdown efficiency was tested. For these studies, complexes were either formulated in water and then diluted 1 volume in 4 in OptiMEM or serumcontaining growth medium, or prepared in OptiMEM and diluted 1 volume in 4 in OptiMEM or serum-containing growth media before adding to the cells, which brought the final water or OptiMEM content to $12.5 \% \mathrm{v} / \mathrm{v}$. All complexes were tested at least in quadruplicates but generally sextuplicates. The final concentration of siRNA in the $100 \mu \mathrm{L}$ in each well was $50 \mathrm{nM}$. Preliminary experiments using LRs prepared using L2K and LPRs made with $\mathbf{K}_{\mathbf{4}} \mathbf{B 1}$-L1-[Y] were performed at siRNA concentrations of $10,30,50$ and $100 \mathrm{nM}$ in $100 \mu \mathrm{L}$ per well to determine the optimal siRNA concentration (Fig. S11, ESI $\dagger$ ). In the case of L2K:siRNA complexes prepared at a lipid:siRA weight ratio of $5: 1$, knockdown efficiency increased with increasing siRNA concentration up to $50 \mathrm{nM}$ whereafter an increase in concentration resulted in a levelling off of knockdown, while cell toxicity (indirectly measured using a protein assay) increased with siRNA concentration, being greatest at $100 \mathrm{nM}$ siRNA. When studying LPRs prepared using $\mathbf{K}_{\mathbf{4}} \mathbf{B 1}-\mathbf{L 1}-[\mathbf{Y}]$ at a charge ratio of $0.5: 12: 1$, a progressive increase in knockdown efficiency was observed upon increasing siRNA dose, however some toxicity was also observed at $100 \mathrm{nM}$ siRNA. For these reasons, $50 \mathrm{nM}$ of siRNA in $100 \mu \mathrm{L}$ per well was used in all subsequent knockdown experiments.

Knockdown experiments were carried out at LPR ratios of $0.5: 6: 1$ and $0.5: 12: 1$, in line with previous studies. ${ }^{29,37}$ Peptide:siRNA (PR) complexes were also tested for selected peptides at 6:1 charge ratio (Fig. S2, ESI $\dagger$ ).

Complexes were added to the cells and incubated for $24 \mathrm{~h}$ at $37{ }^{\circ} \mathrm{C}$. The supernatant was removed and replaced by growth medium and incubated for a further $24 \mathrm{~h}$. Each complex was formulated and tested using Luc-siRNA as well as the negative control siRNA and all knockdown results were expressed as \% knockdown efficiency compared to the luciferase expression produced by the same formulation prepared using the negative control siRNA. A linear relationship between luminescence and protein cell content was measured at protein concentrations of up to $\sim 0.018 \mathrm{mg}$ of protein per well (Fig. S12, ESI $\dagger$ ). The protein content in all subsequent knockdown experiments was therefore monitored to ensure that it fell within the linear region of the luminescence graph.

Luciferase activity, analyzed $48 \mathrm{~h}$ after addition of the complexes, was determined in cell lysates using a commercial luciferase assay according to the manufacturer's protocol. Briefly, cells were rinsed with $50 \mu \mathrm{L}$ phosphate buffered saline (PBS) then lysed by the incubation of $50 \mu \mathrm{L}$ of $1 x$ Reporter Lysis Buffer (provided in the luciferase assay kit) for $1 \mathrm{~h}$ at $25{ }^{\circ} \mathrm{C}$. After freezing the cells for $30 \mathrm{~min}$ at $-80{ }^{\circ} \mathrm{C}$, the lysed cells were thawed and $30 \mu \mathrm{L}$ of the lysate transferred to a white 96-well plate. The luciferase activity was then measured over $10 \mathrm{~s}$ using a MLX Microtitre ${ }^{\circledR}$ Plate Luminometer (Dynex Technologies, USA) after delivering $100 \mu \mathrm{L}$ of the reconstituted Luciferase assay reagent into each well through an automated feeding system.

The amount of protein in each cell lysate was determined using a Pierce BCA Protein Assay kit according to manufacture's instructions. Briefly, the cell lysate $(20 \mu \mathrm{L})$ and bovine serum albumin (BSA) protein standards $(20 \mu \mathrm{L})$ were transferred into a transparent 96 well plate to which mix reagent A/B $(200 \mu \mathrm{L}$, provided in the kit) was added. The plate was incubated with slight shaking at $37{ }^{\circ} \mathrm{C}$ for $30 \mathrm{~min}$ after which time the absorbance was measured at $562 \mathrm{~nm}$ using a SpectraMax 190 plate reader (Molecular Device, USA). All luciferase measurements were normalised against the protein content of each well. Knockdown experiments were repeated on at least two different occasions to confirm that the results were reproducible (results of only one experiment reported).

\section{Confocal fluorescence internalisation studies}

A549-luc cells $\left(1.2 \times 10^{5}\right.$ cells per well $)$ were incubated with LPR complexes in 24-well plates fitted with sterilized $13 \mathrm{~mm}$ circular cover slips (Agar Scientific, UK) as described above with the exception of using fluorescently labelled lipid (10\% of lipid replaced with BODIPY-HPC (green)) and siRNA labelled with TM-Rhodamine (red) using a Label-IT ${ }^{\circledR}$ TM-Rhodamine siRNA Tracker Intracellular Localization Kit according to the manufacturer's protocol. In addition LPRs were also made

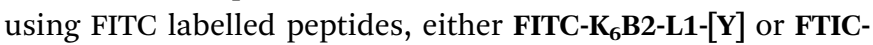
$\left(\mathbf{H}_{3} \mathbf{K}\right)_{\mathbf{4}} \mathbf{B 1}-\mathbf{L 1}-[\mathbf{Y}]$ (green, 100\%) and TM-Rhodamine (red) labelled siRNA and (unlabelled) lipid. The total volume in each well was $400 \mu \mathrm{L}$, with a siRNA concentration of $50 \mathrm{nM}$.

After incubation for $4 \mathrm{~h}$ or $24 \mathrm{~h}$, the complexes were removed and the cells washed once with PBS before fixation of the cells with $4 \% \mathrm{w} / \mathrm{v}$ paraformaldehyde in PBS for $20 \mathrm{~min}$, and permeabilization using $0.2 \% \mathrm{v} / \mathrm{v}$ Triton $\mathrm{X}-100$ solution for $20 \mathrm{~min}$ followed by treatment with $1 \mathrm{mg} \mathrm{mL}^{-1}$ of sodium borohydride in PBS for $5 \mathrm{~min}$. The cell nucleus was stained blue by the 
addition of an aqueous DAPI solution $\left(1 \mu \mathrm{g} \mathrm{mL} \mathrm{m}^{-1}\right)$ for $1 \mathrm{~min}$. The cover slips were washed with PBS several times and mounted onto microscope slides using Mowiol 4-88 mounting media containing $2.5 \% \mathrm{w} / \mathrm{v}$ DABCO. Confocal fluorescence images were acquired on a Leica DMIRE2 confocal fluorescence laser-scanning microscope (Leica Microsystems, Germany).

\section{Acknowledgements}

The authors would like to thank Dr O. Argyros and Prof R. P Harbottle for the episomal S/MAR luciferase vector and Dr M. T. Thanou for providing the stably transfected A549-Luc cell line. EPSRC are thanked for the award of a Nanotechnology Grand Challenge Grant (EP/G061521/1) (to L. K., K. W. and F. C.) and for a DTG studentship to A. M. The MRC are thanked for a studentship to N. D. (G0900207). We also gratefully acknowledge ISIS for the award of neutron beam time and Dr Ann Terry (Instrument Scientist, ISIS) for assistance with the SANS experiments. The expert help of Dr Alex Drake and Dr Tam Bui (Biomolecular Spectroscopy Centre, King's College London) is gratefully acknowledged for the circular dichroism/UV measurements, and the help of Dr Alice Warley (Centre for Ultrastructural Imaging, King's College London) with the TEM measurements is acknowledged.

\section{Notes and references}

1 K. A. Whitehead, R. Langer and D. G. Anderson, Nat. Rev. Drug Discovery, 2009, 8, 129-138.

2 H. M. Aliabadi, B. Landry, C. Sun, T. Tang and H. Uludag, Biomaterials, 2012, 33, 2546-2569.

3 M. A. Mintzer and E. E. Simanek, Chem. Rev., 2009, 109, 259-302.

4 D. L. Gary, N. Puri and Y. Y. Won, J. Controlled Release, 2007, 121, 64-73.

5 K. Jain, P. Kesharwani, U. Gupta and N. K. Jain, Int. J. Pharm., 2010, 394, 122-142.

6 T. Endoh and T. Ohtsuki, Adv. Drug Delivery Rev., 2009, 61, 704-709.

7 Y.-H. Wang, Y.-W. Hou and H.-J. Lee, J. Biochem. Biophys. Methods, 2007, 70, 579-586.

8 S. W. Kim, N. Y. Kim, Y. Bin Choi, S. H. Park, J. M. Yang and S. Shin, J. Controlled Release, 2010, 143, 335-343.

9 P. Kumar, H. Wu, J. L. McBride, K.-E. Jung, M. H. Kim, B. L. Davidson, S. K. Lee, P. Shankar and N. Manjunath, Nature, 2007, 448, 39-43.

10 S.-S. Kim, C. Ye, P. Kumar, I. Chiu, S. Subramanya, H. Wu, P. Shankar and N. Manjunath, Mol. Ther., 2010, 18, 993-1001.

11 P. Kumar, H.-S. Ban, S.-S. Kim, H. Wu, T. Pearson, D. L. Greiner, A. Laouar, J. Yao, V. Haridas, K. Habiro, Y.-G. Yang, J.-H. Jeong, K. Y. Lee, Y.-H. Kim, S.-W. Kim, M. Peipp, G. H. Fey, N. Manjunath, L. D. Shultz, S.-K. Lee and P. Shankar, Cell, 2008, 134, 577-586.
12 P. Midoux, C. Pichon, J.-J. Yaouanc and P.-A. Jaffr"s, Br. J. Pharmacol., 2009, 157, 166-178.

13 Q. Leng, P. Scaria, J. Zhu, N. Ambulos, P. Campbell and A. J. Mixson, J. Gene Med., 2005, 7, 977-986.

14 Q. Leng, P. Scaria, P. Lu, M. C. Woodle and A. J. Mixson, Cancer Gene Ther., 2008, 15, 485-495.

15 S.-T. Chou, Q. Leng, P. Scaria, M. Woodle and A. J. Mixson, Cancer Gene Ther., 2011, 18, 707-716.

16 S.-T. Chou, Q. Leng, P. Scaria, J. D. Kahn, L. D. Tricoli, M. Woodle and A. J. Mixson, Biomacromolecules, 2013, 14, 752-760.

17 B. Langlet-Bertin, C. Leborgne, D. Scherman, B. Bechinger, A. J. Mason and A. Kichler, Pharm. Res., 2010, 27, 1426-1436.

18 D. L. McKenzie, E. Smiley, K. Y. Kwok and K. G. Rice, Bioconjugate Chem., 2000, 11, 901-909.

19 M. L. Read, S. Singh, Z. Ahmed, M. Stevenson, S. S. Briggs, D. Oupicky, L. B. Barrett, R. Spice, M. Kendall, M. Berry, J. A. Preece, A. Logan and L. W. Seymour, Nucleic Acids Res., 2005, 33, e86.

20 M. F. Mohd Mustapa, P. C. Bell, C. A. Hurley, A. Nicol, E. Guénin, S. Sarkar, M. J. Writer, S. E. Barker, J. B. Wong, M. A. Pilkington-Miksa, B. Papahadjopoulos-Sternberg, P. A. Shamlou, H. C. Hailes, S. L. Hart, D. Zicha and A. B. Tabor, Biochemistry, 2007, 46, 12930-12944.

21 A. D. Miller, Angew. Chem., Int. Ed., 1998, 37, 1768-1785.

22 M. J. Writer, B. Marshall, M. A. Pilkington-Miksa, S. E. Barker, M. Jacobsen, A. Kritz, P. C. Bell, D. H. Lester, A. B. Tabor, H. C. Hailes, N. Klein and S. L. Hart, J. Drug Targeting, 2004, 12, 185-194.

23 J. B. Wong, S. M. Grosse, A. B. Tabor, S. L. Hart and H. C. Hailes, Mol. BioSyst., 2008, 4, 532-541.

24 C. A. Hurley, J. B. Wong, J. Ho, M. Writer, S. A. Irvine, M. J. Lawrence, S. L. Hart, A. B. Tabor and H. C. Hailes, Org. Biomol. Chem., 2008, 6, 2554-2559.

25 M. F. Mohd Mustapa, S. M. Grosse, L. Kudsiova, M. Elbs, E.-A. Raiber, J. B. Wong, A. P. R. Brain, H. E. J. Armer, A. Warley, M. Keppler, T. Ng, M. J. Lawrence, S. L. Hart, H. C. Hailes and A. B. Tabor, Bioconjugate Chem., 2009, 20, 518-532.

26 S. M. Grosse, A. D. Tagalakis, M. F. Mohd Mustapa, M. Elbs, Q.-H. Meng, A. Mohammadi, A. B. Tabor, H. C. Hailes and S. L. Hart, FASEB J., 2010, 24, 2301-2313.

27 L. Kudsiova, B. Fridrich, J. Ho, M. F. Mohd Mustapa, F. Campbell, K. Welser, M. Keppler, T. Ng, D. J. Barlow, A. B. Tabor, H. C. Hailes and M. J. Lawrence, Mol. Pharmaceutics, 2011, 8, 1831-1847.

28 L. Kudsiova, J. Ho, B. Fridrich, R. Harvey, M. Keppler, T. Ng, S. L. Hart, A. B. Tabor, H. C. Hailes and M. J. Lawrence, Mol. BioSyst., 2011, 7, 422-436.

29 K. Welser, F. Campbell, L. Kudsiova, A. Mohammadi, N. Dawson, S. L. Hart, D. J. Barlow, H. C. Hailes, M. J. Lawrence and A. B. Tabor, Mol. Pharmaceutics, 2013, 10, 127-141.

30 J. J. Turner, S. W. Jones, S. A. Moschos, M. A. Lindsay and M. J. Gait, Mol. BioSyst., 2007, 3, 43-50. 
31 G. Siligardi and A. F. Drake, Biopolymers, 1995, 37, 281-292. 32 D. Gray, Circular Dichroism of Protein-Nucleic Acid Interactions, Circular Dichroism and the Conformational Analysis of Biomolecules, (The Language of Science), ed. G. Fasman, Plenum Press, New York, 1996, pp. 469-500.

33 R. W. Woody, Methods Enzymol., 1995, 246, 34-71.

34 J. O. Radler, I. Koltover, T. Salditt and C. R. Safinya, Science, 1997, 275, 810-814.
35 B. Pitard, O. Aguerre, M. Airiau, A.-M. Lachages, T. Boukhinkachvili, G. Byk, C. Dubertret, C. Herviou, D. Scherman, J.-F. Mayaux and J. Crouzet, Proc. Natl. Acad. Sci. U. S. A., 1997, 94, 14412-14417.

36 O. Argyros, S. P. Wong, K. Gowers and R. P. Harbottle, PLoS One, 2012, 7, e47920.

37 A. D. Tagalakis, L. He, L. Saraiva, K. T. Gustafsson and S. L. Hart, Biomaterials, 2011, 32, 6302-6315. 